\title{
Experimentally induced testicular dysgenesis syndrome originates in the masculinization programming window
}

Sander van den Driesche, ${ }^{1}$ Karen R. Kilcoyne, ${ }^{1}$ Ida Wagner, ${ }^{1}$ Diane Rebourcet, ${ }^{1}$ Ashley Boyle, ${ }^{1}$ Rod Mitchell, ${ }^{1}$ Chris McKinnell, ${ }^{1}$ Sheila Macpherson, ${ }^{1}$ Roland Donat, ${ }^{2}$ Chitranjan J. Shukla, ${ }^{2}$ Anne Jorgensen, ${ }^{3}$ Ewa Rajpert-De Meyts, ${ }^{3}$ Niels E. Skakkebaek, ${ }^{3}$ and Richard M. Sharpe ${ }^{1}$

'MRC Centre for Reproductive Health, The Queen's Medical Research Institute, University of Edinburgh, Edinburgh, United Kingdom. ${ }^{2}$ Edinburgh Urological Cancer Group, Department of Urology, Western General Hospital, Edinburgh, United Kingdom. ${ }^{3}$ Department of Growth \& Reproduction, Copenhagen University Hospital (Rigshospitalet), Copenhagen, Denmark.

The testicular dysgenesis syndrome (TDS) hypothesis, which proposes that common reproductive disorders of newborn and adult human males may have a common fetal origin, is largely untested. We tested this hypothesis using a rat model involving gestational exposure to dibutyl phthalate (DBP), which suppresses testosterone production by the fetal testis. We evaluated if induction of TDS via testosterone suppression is restricted to the "masculinization programming window" (MPW), as indicated by reduction in anogenital distance (ACD). We show that DBP suppresses fetal testosterone equally during and after the MPW, but only DBP exposure in the MPW causes reduced AGD, focal testicular dysgenesis, and TDS disorders (cryptorchidism, hypospadias, reduced adult testis size, and compensated adult Leydig cell failure). Focal testicular dysgenesis, reduced size of adult male reproductive organs, and TDS disorders and their severity were all strongly associated with reduced ACD. We related our findings to human TDS cases by demonstrating similar focal dysgenetic changes in testes of men with preinvasive germ cell neoplasia (CCNIS) and in testes of DBP-MPW animals. If our results are translatable to humans, they suggest that identification of potential causes of human TDS disorders should focus on exposures during a human MPW equivalent, especially if negatively associated with offspring ACD.

Authorship note: S. van den Driesche and K.R. Kilcoyne contributed equally to this work.

Conflict of interest: The authors have declared that no conflict of interest exists.

Submitted: October 13, 2016

Accepted: February 8, 2017

Published: March 23, 2017

Reference information: JCI Insight. 2017;2(6):e91204. https:// doi.org/10.1172/jici.nsight.91204

\section{Introduction}

Disorders of human male reproductive health that manifest at birth (cryptorchidism, hypospadias) or in young adulthood (low sperm count, testicular germ cell cancer [TGCC], primary hypogonadism) are remarkably common, and some, at least, are increasing in incidence (1-3). In Northern Europe, about 1 in 6 young men will have one or more of these disorders (3-5). It has been hypothesized that these disorders may comprise a testicular dysgenesis syndrome (TDS) with a common origin in fetal life $(3,6,7)$, perhaps related to subtle deficiencies in fetal androgen (testosterone) production or action (8). The original motivation for this hypothesis was the discovery that TGCC that occurs in young men arises because of a failure of fetal germ cells (gonocytes) to differentiate normally $(3,6,9,10)$ and that risk of TGCC is related to other TDS disorders $(3,6)$

While the fetal origin of cryptorchidism and hypospadias is self-evident, it is not an obvious explanation for adult-onset disorders, such as low sperm count and hypogonadism, which involve processes and cells that do not emerge until after puberty. Moreover, testing whether such adult-onset disorders originate in fetal life is challenging in humans, as it requires "looking back in time" over 20 or more years $(2,11)$. Consequently, the TDS hypothesis remains largely untested and unproven $(12,13)$, although circumstantial supporting evidence from clinical studies has grown progressively $(1,3,5,14,15)$. If the TDS hypothesis was proved correct, it would refocus research effort in humans toward identifying causal factors acting via the pregnant mother that might be preventable.

The TDS hypothesis focused on "dysgenesis," because adult men with TDS disorders often exhibit focal morphological abnormalities of the testis, such as abnormal-shaped seminiferous tubules, Leydig cell 
nodules, or Sertoli cell-only (SCO) tubules, in which the Sertoli cells are often visibly undifferentiated (3, 7, 16-18). This was interpreted as evidence for abnormal early development of the testis, which then led, secondarily, to impaired functions of fetal somatic or germ cells, culminating in TDS disorders $(3,6)$. In this regard, it is important to highlight that, while gross impairment of early testis development can result in overt dysgenesis and resulting downstream effects $(18,19)$, the primary focus of the TDS hypothesis is on men in whom the dysgenetic changes are focal, often in an otherwise largely normal testis (16-18). However, it is impossible to identify that such focal dysgenesis in testes of adult men originates from maldevelopment of the fetal testis.

Understanding of the fetal origins of male reproductive disorders in laboratory animals changed dramatically in 2008 with the discovery of the "masculinization programming window" (MPW) (20). The MPW refers to the window of time during fetal development in which androgen actions program later development of all male reproductive organs, including their ultimate adult size and function (20-22). A vital finding was that anogenital distance (AGD), which is normally about twice as long in rodent males as in females, was also programmed by androgen action within the MPW (20, 23). Hence, AGD could be measured at any postnatal age in rats and used to retrospectively decipher the level of fetal androgen exposure during the MPW $(11,21)$. In human males, AGD shows similar male-female differences as in rats (11, 24-26), and lower AGD has been related to the occurrence of TDS disorders evident at birth (27-33) and, in a majority of studies, to lower sperm counts $(34-37)$ and hormone levels $(38,39)$ in adult men, similar to rats (reviewed in ref. 11). Such findings are consistent with the TDS hypothesis and suggest, but do not prove, that TDS disorders in men may originate within a MPW.

Because of inherent limitations in human studies, the TDS hypothesis can realistically only be tested using an animal model approach. Identification of the MPW in rodents was based on use of the androgen receptor antagonist flutamide (20), but in humans TDS is considered to result from maldevelopment and consequent malfunction of the fetal testis $(3,6)$, so that a model with such changes was needed. Our earlier studies suggested that exposure of pregnant rats to the environmental chemical dibutyl phthalate (DBP) might be a potential model for TDS in humans, as the testis differentiates normally after DBP exposure (40), but this treatment induces focal dysgenesis (40-42) and reduces fetal testis testosterone levels via effects on steroidogenic gene expression (43-45), which then causes TDS disorders (41, 42, 46). However, such studies were undertaken before the importance of the MPW had been identified. Thus, the hypothesis we tested in the present study had two aims: first, to assess if DBP-induced TDS disorders, that manifest at birth or in adulthood, are only inducible by DBP exposure (and associated androgen deficiency) during the MPW and second, to establish what relationship these changes had to focal testicular dysgenetic changes, comparable to those evident in human TDS cases. Our results show that only DBP exposure during the MPW results in TDS disorders and that this is intrinsically linked to occurrence of focal dysgenesis, even when DBP exposure commenced after normal testis differentiation and early development. Our findings also reaffirm (20) that AGD provides a specific, lifelong "readout" of the level of androgen exposure during the MPW. We suggest that these findings provide robust animal model validation of the TDS hypothesis and, assuming their translation to the human, they have fundamental health and research implications.

\section{Results}

Comparative fetal effects of DBP exposure $(750 \mathrm{mg} / \mathrm{kg} / \mathrm{d})$ during the $M P W(E 15.5-E 18.5)$ or immediately after this period (late window; E19.5-E20.5). Most morphological signs of androgen-driven masculinization emerge in the rat fetus during the period from E18.5 to E21.5 after the MPW, but these changes are actually induced (programmed) by androgen exposure in the prior MPW (20). Hence, we used differential DBP exposure during the MPW or in the period immediately afterward (late window [LW]) to evaluate the relative importance of DBP-induced differences in androgen exposure in the MPW and LW in the origin of TDS disorders.

DBP exposure during either the MPW or LW caused comparable suppression (47\%-48\%) of intratesticular testosterone (ITT) in male fetuses when measured 48 hours after the commencement of daily DBP treatment (Figure 1A). In fetuses exposed to DBP only during the MPW, ITT levels had recovered to near normal by E21.5 (Figure 1A). Despite the similar magnitude of DBP-induced suppression of ITT during the MPW and the LW, only male rat fetuses exposed to DBP during the MPW exhibited a significant reduction in AGD at E21.5 (Figure 1B). At E17.5 (during the MPW), the only detectable morphological effect of DBP exposure was central aggregation of fetal Leydig cells in comparison with controls (compare 
Figure 1C and Figure 1D); in earlier studies, we showed that DBP treatment does not alter fetal Leydig cell number (47). Fetal Leydig cell aggregation induced by DBP exposure during the MPW was still evident at E21.5 (Figure 1F) but was not present in controls (Figure 1E) or in DBP-treated animals in the LW (DBPLW) (Figure 1G). At E21.5, but not at E17.5 (during DBP exposure; Figure 2, A and B), an additional change, which was confined to the DBP-MPW-exposed group, manifested as the appearance of numerous ectopic Sertoli cells in approximately $80 \%$ of fetuses, scattered among the aggregated fetal Leydig cells (Figure 2, D and F). In contrast, ectopic Sertoli cell number in the DBP-LW group remained at background levels, comparable to controls (Figure 2, C, E, and F). Therefore, DBP induction of focal dysgenesis (Leydig cell aggregation, ectopic Sertoli cells) in the fetal testis requires DBP exposure during the MPW and is not inducible by DBP-LW exposure.

Reproductive organ weights of adult male rats following DBP-induced androgen deficiency in fetal life. Rats in the DBP-LW group exhibited a normal adult phenotype, indistinguishable from controls with respect to testis weight, penis length, prostate weight, and AGD (Figure 3, A-D). In contrast, adult males from the DBPMPW group exhibited significant reductions in all of these parameters compared with controls (Figure 3 , A-D). We also evaluated whether exposure of rats to DBP from E13.5 to E21.5 (full window [FW]), which encompassed the 2 days before the MPW (when testis differentiation occurs), the MPW, and the LW, induced a more severe reproductive phenotype than DBP exposure just during the MPW. Unexpectedly, we found evidence for the opposite, as the adverse reproductive changes in adult rats from the DBP-MPW group were consistently more marked than in those from the DBP-FW group, although this difference was only statistically significant for AGD and penis length (Figure 3, A-D). Using AGD as a "readout" of the level of androgen exposure during the MPW (19), it was evident that testis size (Figure 3E), penis length (Figure 3F), and prostate weight (Figure $3 \mathrm{G}$ ) were all strongly correlated with AGD when data from all adult males in this study were analyzed together.

Occurrence of cryptorchidism and hypospadias in adult rats following DBP-induced androgen deficiency in fetal life. Rats from the DBP-MPW group exhibited a high incidence of cryptorchidism (64\%) and hypospadias $(52 \%)$, whereas no cases of these disorders occurred in controls and only 1 male in the DBP-LW group had a mild glanular hypospadias (Figure 4A). The induced cryptorchidism was bilateral in $69.7 \%$ of DBP-MPWexposed rats and unilateral in the remainder. Similarly, in the DBP-MPW group, the induced hypospadias was severe (perineal) in $73.1 \%$ of rats with this disorder and mild to moderate in the remainder; in severe cases, there was also marked chordee.

When adult rats in the study were categorized according to the absence or presence of a genital abnormality (and, if present, its severity), irrespective of their treatment group, it was evident that the more severe the genital abnormality, the smaller the AGD (Figure 4B). Thus, animals with bilateral cryptorchidism had significantly shorter $(P<0.001)$ AGD than did animals with unilateral cryptorchidism, and the latter had significantly shorter $(P<0.001)$ AGD than did animals with bilateral scrotal testes (Figure 4B). A similar trend was evident for grades of hypospadias. Animals with severe hypospadias had significantly shorter $(P<0.001)$ AGD than either rats without hypospadias or rats with mild or moderate hypospadias, with AGD in the latter group being significantly shorter $(P<0.05)$ than in animals with a normally positioned penile urethral opening (Figure 4B).

Effect of DBP-induced androgen deficiency in fetal life on adult Leydig cell function. We have shown previously that deficiency in fetal androgen action in rats/mice results in "compensated Leydig cell failure" in adulthood (48), so we evaluated if such effects were also connected to the MPW. Exposure to DBP in either the MPW or LW did not alter mean plasma levels of testosterone in adulthood (Figure 5A). However, rats from the DBP-MPW group exhibited marked elevation of plasma luteinizing hormone (LH) levels in comparison with controls (Figure 5B) and, thus, had a distorted LH/log testosterone ratio (Figure 5C) indicative of compensated Leydig cell failure (5, 48, 49). DBP-MPW-induced compensated Leydig cell failure was evident in animals with scrotal or cryptorchid testes, although the magnitude of the effect was significantly greater for animals with cryptorchid testes (Figure 5C). In contrast, DBP-LW rats had normal LH levels and did not exhibit compensated Leydig cell failure (Figure 5, B and C). Consistent with the hypothesis that compensated Leydig cell failure originates from DBP-induced testosterone suppression in the MPW, a significant negative correlation was found between AGD and the LH/log testosterone ratio when data for all animals in the study were analyzed together (Figure 5D). A similar negative relationship was found between the $\mathrm{LH} / \log$ testosterone ratio and average testis weight, which can be equated to the number of germ cells/sperm production (Figure $5 \mathrm{E}$ ). 
A

5

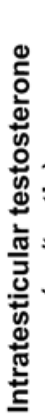

e17.5
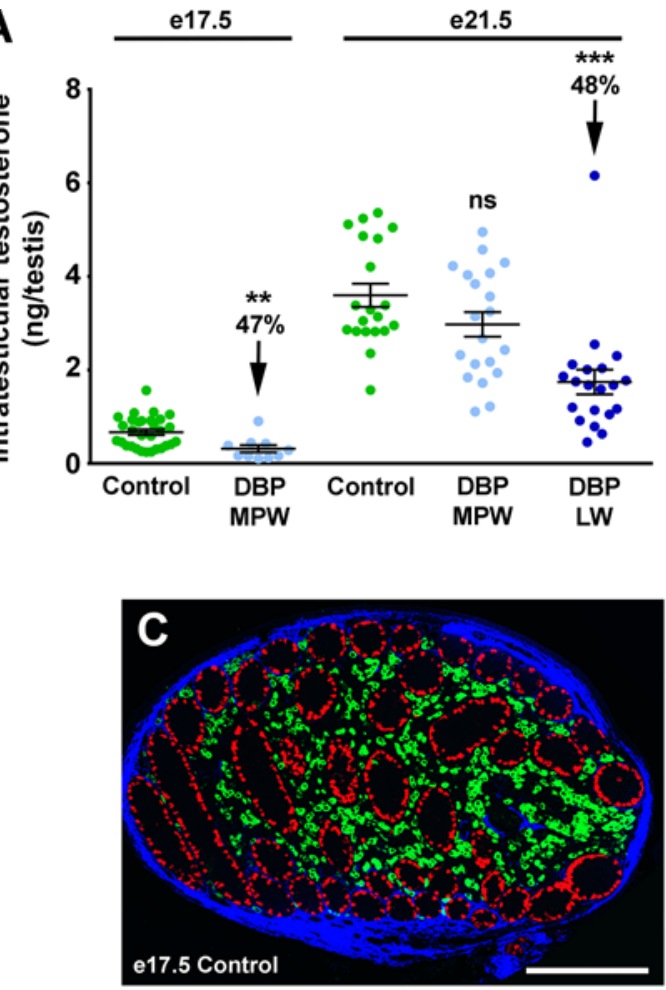

B

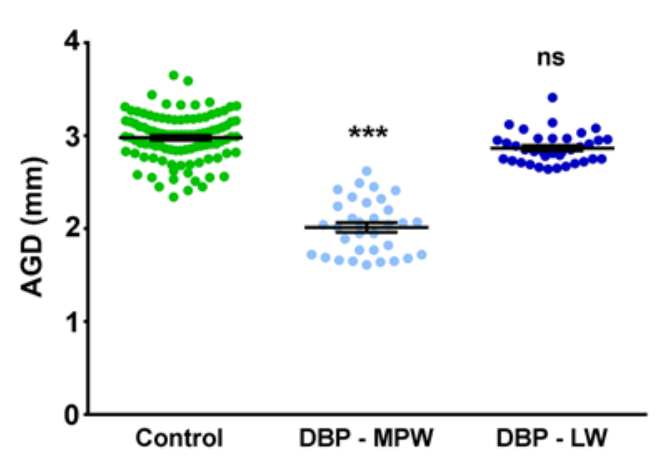

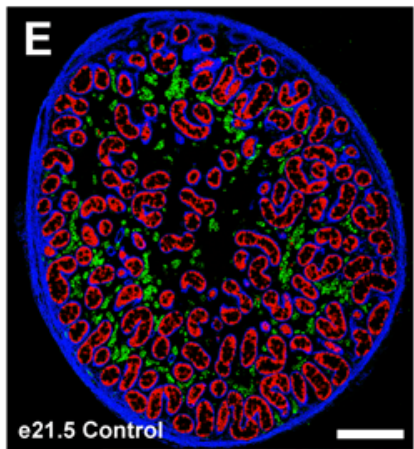
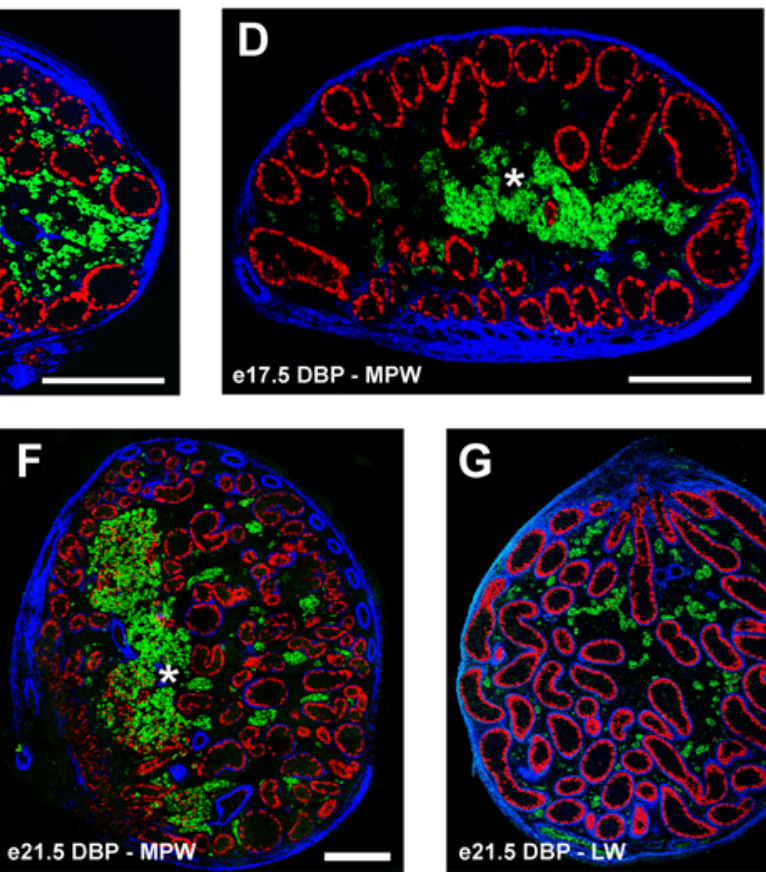

Figure 1. Effect of fetal exposure of rats to dibutyl phthalate during the masculinization programming window or immediately afterward (late window) on intratesticular testosterone, anogenital distance, and gross testis morphology at E17.5 and E21.5. Intratesticular testosterone (A), anogenital distance (B), and gross testis morphology (C-G) at E17.5 and E21.5. Note that E17.5 is during the MPW, E21.5 is at the end of the LW. (A and B) Values are mean \pm SEM, with analysis by 2 -tailed Student's $t$ test or ANOVA with Bonferroni correction ( ${ }^{* *} P<0.01$, ${ }^{* *} P<0.001$, compared with respective control). (C-G) Sections were triple immunostained for SOX9 (red; Sertoli cells), 33-HSD (green; Leydig cells), and smooth muscle actin (blue). Asterisks indicate abnormal aggregation of fetal Leydig cells (green). Scale bars: $200 \mu$ M. DBP, dibutyl phthalate; MPW, masculinization programming window; LW, late window; AGD, anogenital distance.

Dysgenetic features in the adult testes of DBP-exposed rats. DBP exposure in utero induces histological changes in the testis that are evident in adulthood as focal dysgenetic areas $(41,42,50)$ (Supplemental Figure 1; supplemental material available online with this article; https://doi.org/10.1172/jci. insight.91204DS1). It has not been evaluated previously whether DBP-induced dysgenesis is confined to animals exposed specifically during the MPW. Therefore, we systematically evaluated the testes of representative adult rats from the control, DBP-MPW, and DBP-LW groups to evaluate 4 specific dysgenetic features (see Figure 6 for examples), namely the occurrence of (a) focal dysgenetic areas (focal groups of malformed seminiferous tubules), (b) seminiferous tubules with a subnormal germ cell complement (impaired spermatogenesis), (b) SCO tubules, and (d) tubules with intratubular Leydig cells. For the DBPMPW group, we analyzed 6 rats with bilateral or unilateral cryptorchidism and 13 rats with noncryptorchid testes, which included testes that were normally scrotal $(n=6)$ as well as those that were labeled as inguinal $(n=7)$; the latter were defined at necropsy as testes that were scrotal/high scrotal, but which had 

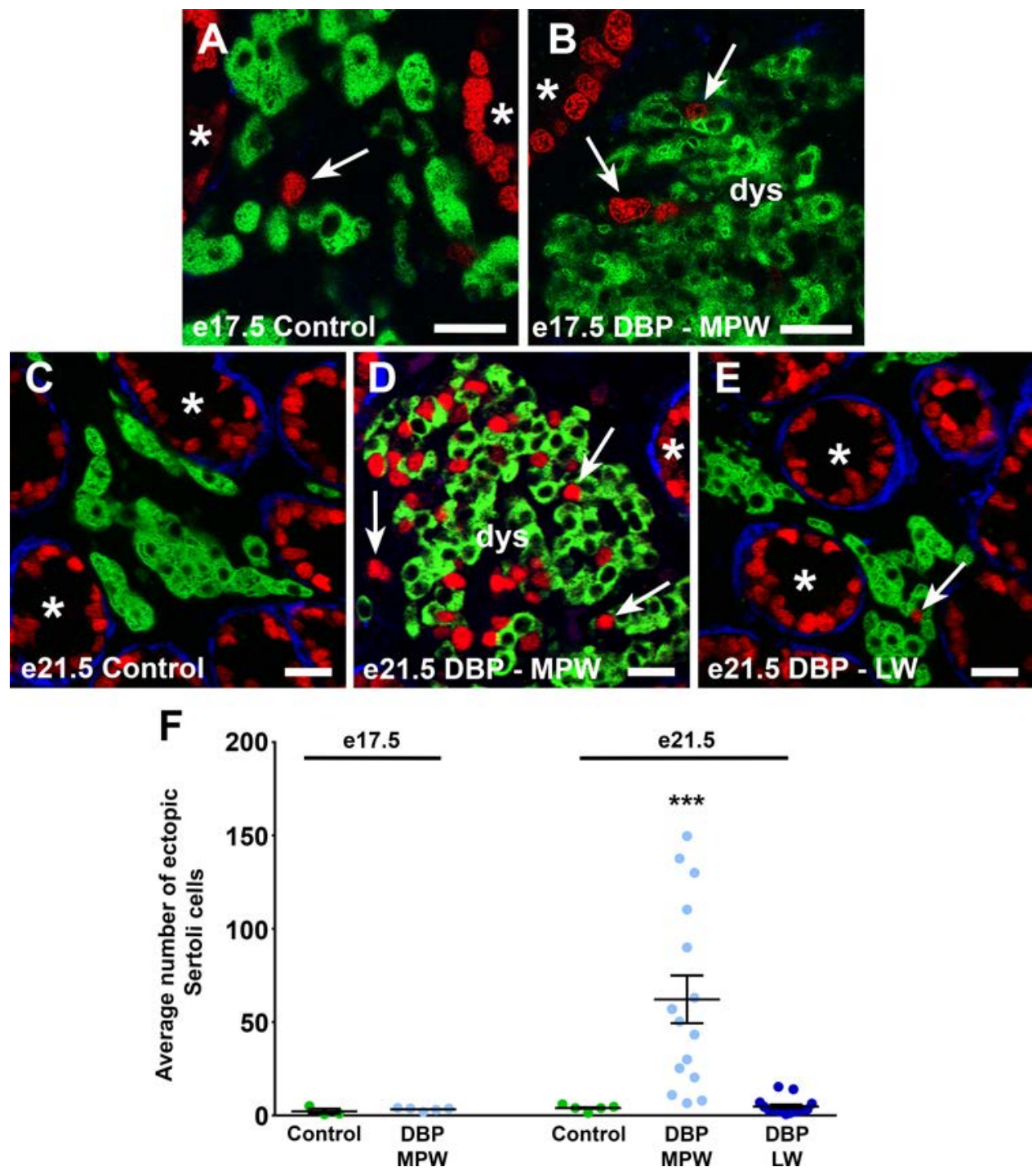

Figure 2. Dibutyl phthalate-induced dysgenesis of the fetal testis at E17.5 (Leydig cell aggregation) or E21.5 (increased numbers of ectopic Sertoli cells) occurs after exposure in the masculinization programming window but not the late window. Note that E17.5 is during the MPW, E21.5 is at the end of the LW. (A-E) Sections were triple immunostained for SOX9 (red; Sertoli cells), 3ß-HSD (green; Leydig cells), and smooth muscle actin (SMA) (blue; peritubular myoid cells). Asterisks indicate normal seminiferous cords, and white arrows show examples of ectopic Sertoli cells, numbers of which were increased selectively at E21.5 ( $D$ and $\mathbf{F}$ ) but not at E17.5 (B and $\mathbf{F}$ ) in the DBP-MPW group; there was no change in ectopic Sertoli cells or fetal Leydig cell aggregation at E21.5 in the DBP-LW group (F). Scale bars: $20 \mu \mathrm{M}$. (F) Values are mean \pm SEM, with analysis by 2-tailed Student's $t$ test (E17.5) or ANOVA with Bonferroni correction (E21.5) ${ }^{* * *} P<$ 0.001 , in comparison to E21.5 control). DBP, dibutyl phthalate; dys, dysgenesis; MPW, masculinization programming window; LW, late window.

an absent or abnormally elongated gubernacular ligament, meaning that the testis could not be normally anchored in the scrotum. This phenotypic selection was reflective of the DBP-MPW treatment group as a whole and enabled us to evaluate whether focal dysgenesis was related to testis position/phenotype. All testes from control and DBP-LW animals were scrotal. To facilitate identification of focal dysgenetic features, whole testis cross sections ( 2 per rat from different testis areas) were immunostained for VASA

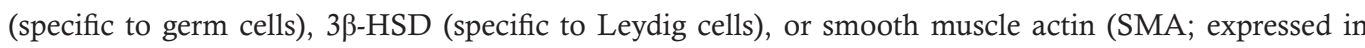
peritubular myoid cells and blood vessels) to delineate seminiferous tubule boundaries.

Adult rats from the DBP-LW group $(n=6)$ showed no focal dysgenetic features in their testes and were thus comparable to controls (Figure 6, A, C, and E). In contrast, rats from the DBP-MPW group exhibited frequent occurrence of one or more focal dysgenetic features (Figure 6). Focal dysgenesis was most common in cryptorchid testes, $100 \%$ of which exhibited two or more focal dysgenetic features, whereas only approximately $70 \%$ of noncryptorchid testes exhibited one or more focal dysgenetic features. The least commonly observed focal dysgenetic feature was intratubular Leydig cells (Supplemental Figure 2). Overall, focal dysgenesis within the testis was more common in animals with a genital abnormality (i.e., cryptorchidism) (Figure 6).

Dysgenetic features in the testes of human TDS cases. Testicular dysgenesis encompasses a spectrum ranging from testes that are completely malformed (probably accompanied by lack of virilization) to testes in which only patchy/focal areas of the testis may be abnormal (focal dysgenesis) and in which the affected men are normally virilized and devoid of other nonreproductive pathologies $(18,51)$. An example of the latter is young men with preinvasive TGCC, i.e., intratubular germ cell neoplasia in situ (GCNIS; refs. 9, 
A

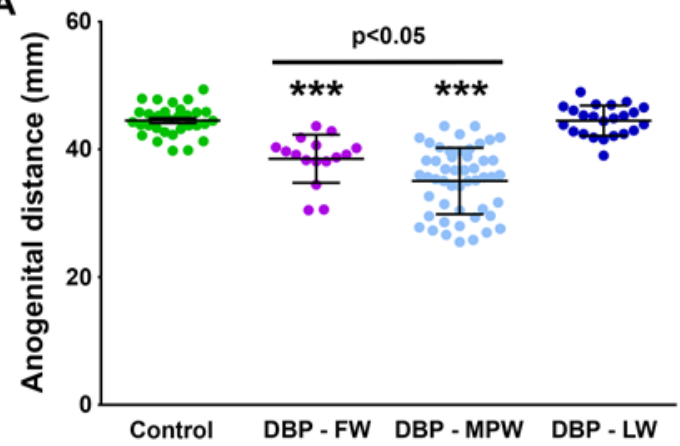

C

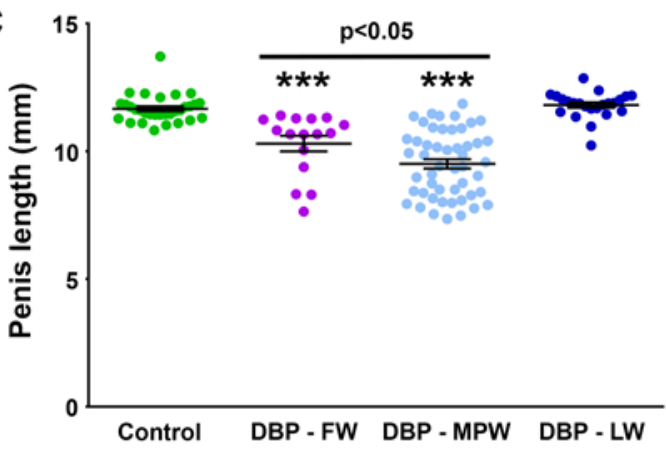

B

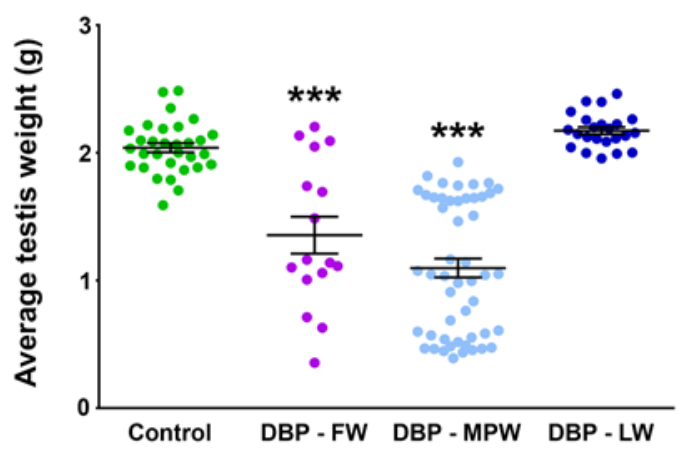

D

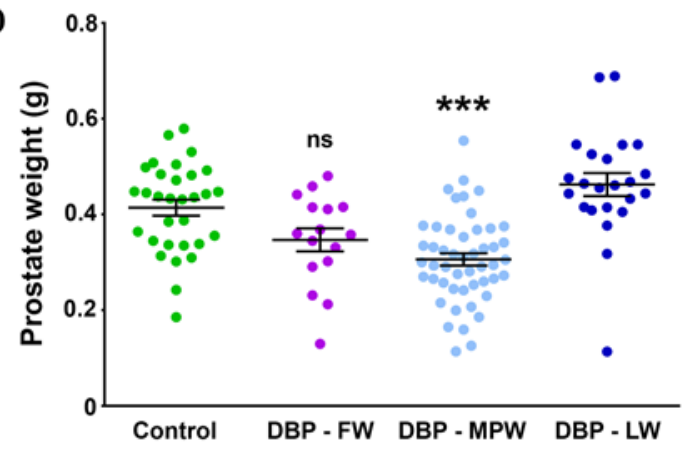

E

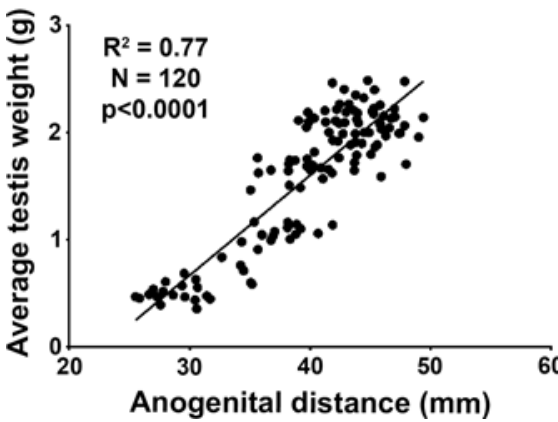

F

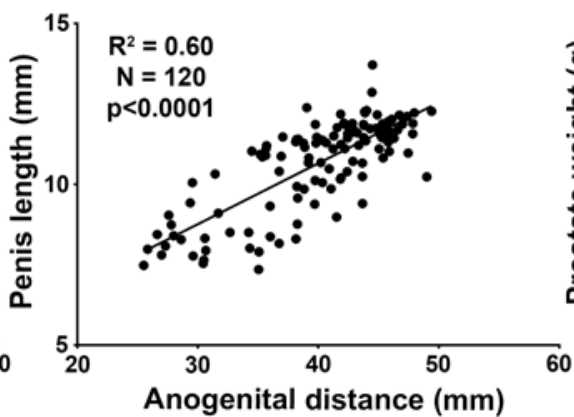

G

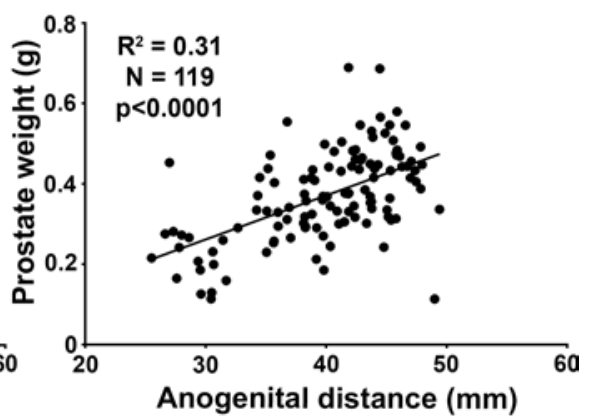

Figure 3. Dibutyl phthalate exposure in the masculinization programming window, but not the late window, reduces anogenital distance and reproductive organ size in adulthood. (A) Anogenital distance and (B-D) reproductive organ size in adulthood in the different treatment groups. Data are also shown for rats exposed to DBP during the FW (E13.5-E21.5), which encompasses the MPW and LW. Values are mean \pm SEM, with analysis by ANOVA with Bonferroni correction ( ${ }^{* *} P<0.001$, in comparison to respective control). (E-C) Linear correlation between anogenital distance and adult reproductive organ size for all animals from the treatment groups in A-D. DBP, dibutyl phthalate; FW, full window; MPW, masculinization programming window; LW, late window.

10, 18), who constitute the definitive TDS case (6). We specifically selected 10 such samples from a tissue archive on the basis of the presence of GCNIS (but no TGCC); their mean age was 29.6 years (range, 17-44 years). Although we cannot definitively exclude that these men might have had another condition that could affect testicular histology, to reduce the chances of such confounding, we used as one of our control groups GCNIS-free ("normal") biopsies from the contralateral testes of men who had been diagnosed with TGCC $(n=8)$, who might be expected to be at equivalent risk of having an unrelated condition affecting their testes (52). These biopsies had been taken to establish if GCNIS was present and proved to be negative based on routine histological and immunohistochemical analyses; the mean age of the men providing these biopsies was 38.8 years (range $33-50$ years). As approximately $15 \%$ of such testes may still harbor dysgenetic features (16), a second group of controls $(n=4)$ was examined, these being men having a mean age of 40 years (range 33-52 years) in whom one testis had been removed because of chronic pain and in which no histological evidence for testicular abnormality was found. As no significant differences were found between these two control groups, they were pooled for comparison with the GCNIS preinvasive TGCC group. We evaluated 


\section{A Relationship of DBP treatment window to genital phenotype}

\section{Percentage of hypospadias}

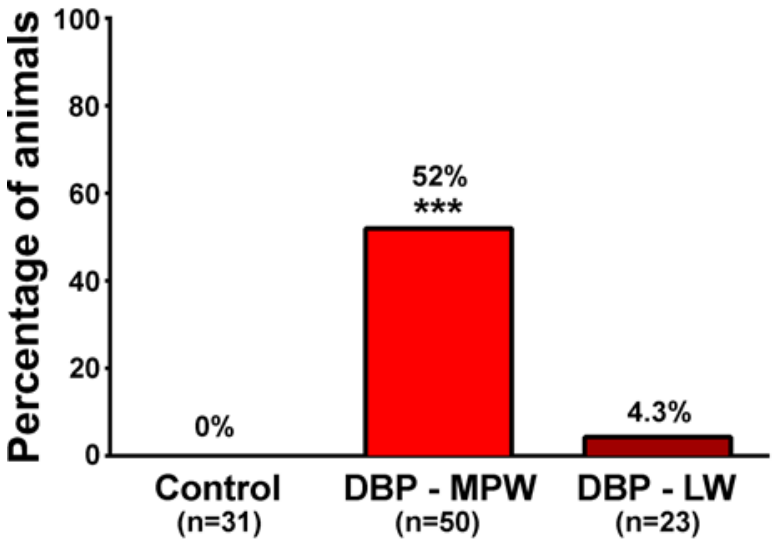

Percentage of cryptorchidism

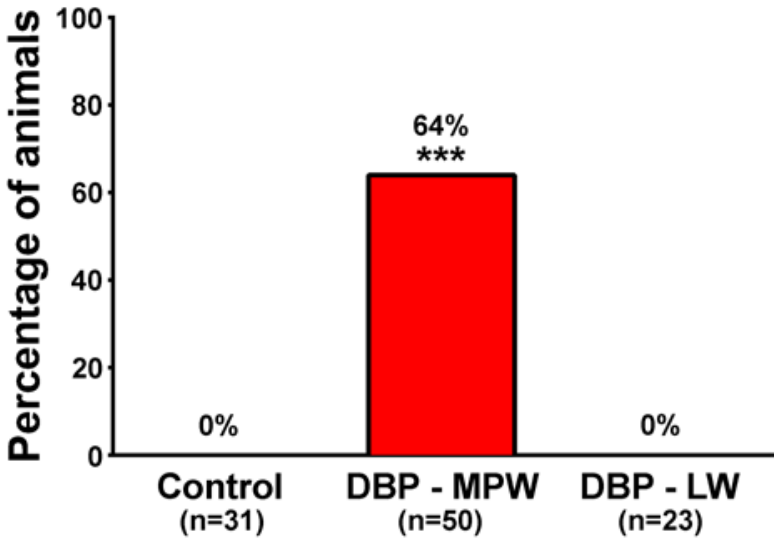

B

Relationship of genital phenotype to AGD
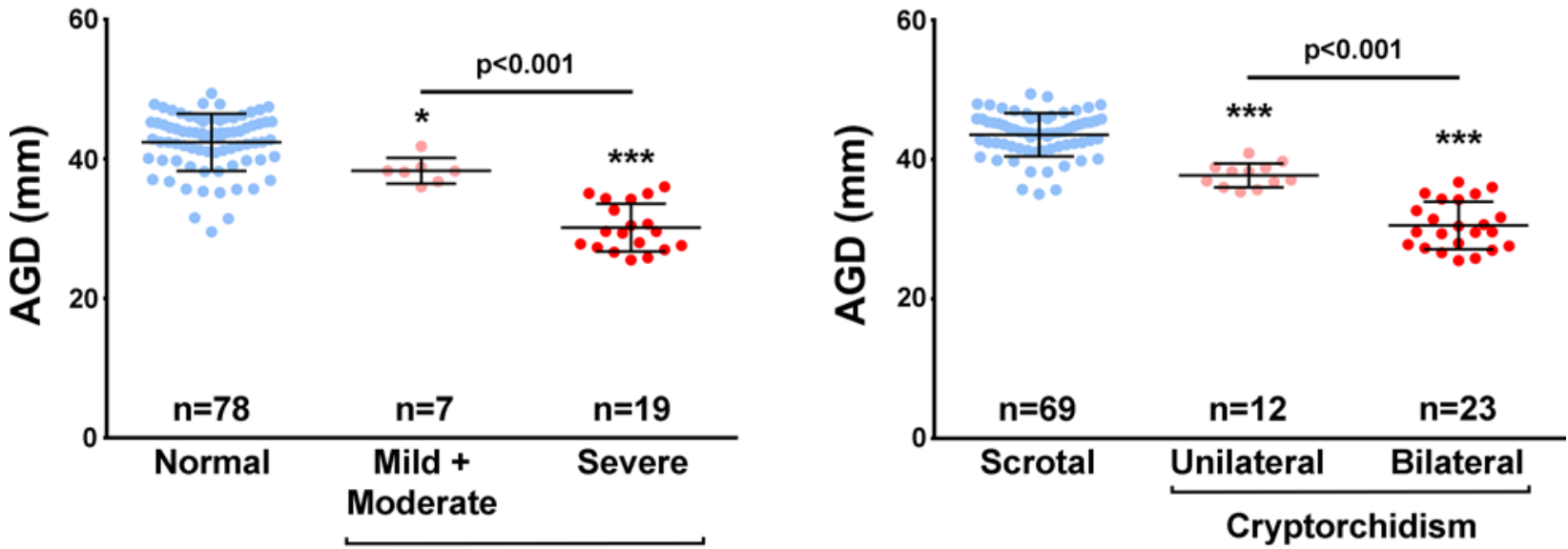

Hypospadias

Figure 4. Dibutyl phthalate exposure in the masculinization programming window, but not the late window, increases incidence of hypospadias and cryptorchidism in adulthood. (A) The relationship between genital phenotype and DBP treatment window. (B) The relationship between genital phenotype and ACD for all rats from the treatment groups in $\mathbf{A}$. Data in $\mathbf{A}$ were analyzed using Fisher's exact test with Bonferroni correction (*** $P<0.001$, in comparison to respective control group); data in B (mean \pm SEM) were analyzed by ANOVA with Bonferroni correction $\left({ }^{*} P<0.05\right.$, ${ }^{* * *} P<0.001$, in comparison to rats with a phenotypically normal penis [bottom left] or with bilateral scrotal testes [bottom right]). DBP, dibutyl phthalate; MPW, masculinization programming window; LW, late window; AGD, anogenital distance.

the occurrence of focal dysgenesis in these 3 groups of men using the same identification criteria as that used in the rat DBP studies reported above to enable comparison of human and rat TDS cases.

In control men, no focal dysgenetic areas (abnormally formed tubules) were found (Figure 7A), but 3 of 12 men had a few scattered seminiferous tubules $(3.0 \% \pm 0.2 \%$; mean $\pm \mathrm{SEM} ; n=3)$ classified as being SCO or having a subnormal germ cell complement (Figure 7, D and G). In contrast, all 10 men with preinvasive TGCC exhibited one or more testicular dysgenetic features. Focal dysgenetic areas were found in 6 of the 10 men with preinvasive TGCC (Figure 7, A-C). However, the most common features were SCO tubules and tubules with abnormal spermatogenesis (Figure 7, D-I), which affected $43.2 \% \pm$ $6.8 \%$ (mean \pm SEM, $n=10$ ) of all tubules evaluated; this was notably more extensive than in the 3 control men who exhibited such features $(P=0.007$; Mann-Whitney test). Intratubular Leydig (CYP11a1-immunopositive) cells were not identified in any of the 10 preinvasive TGCC samples or in controls. We decided not to extend our quantitative analysis of dysgenetic features to men with low sperm counts because we did not have any definitive means of proving that any abnormalities found could be attributed to 
A

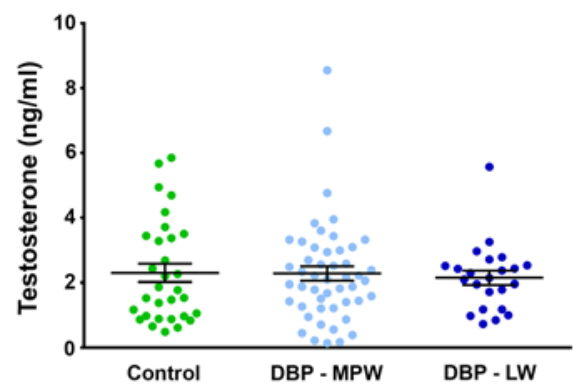

B

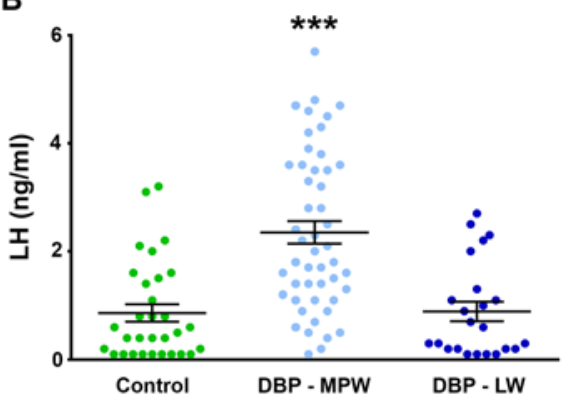

C

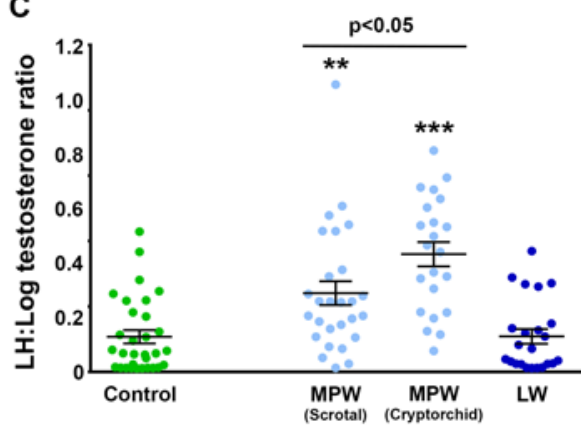

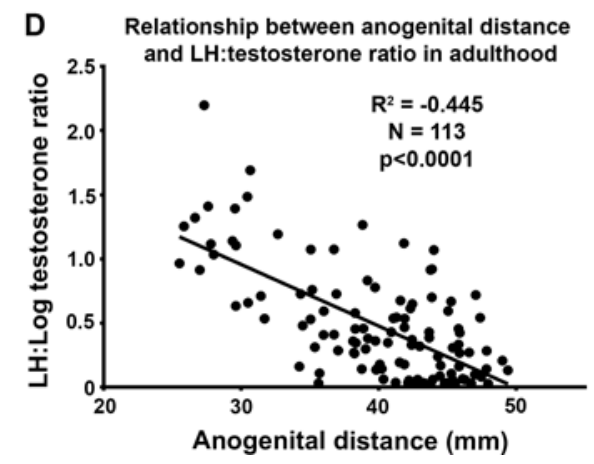

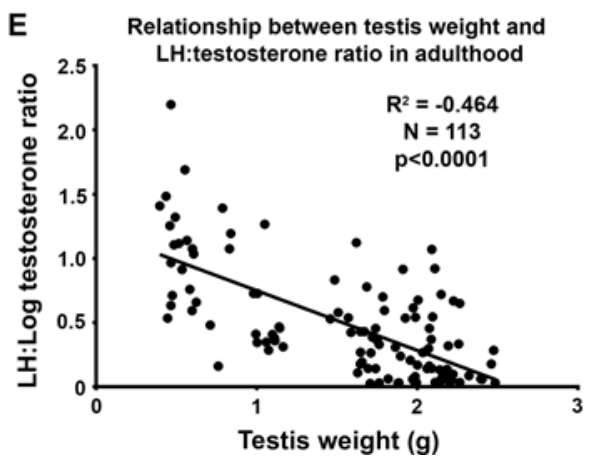

DBP treatment window

Figure 5. Dibutyl phthalate exposure in the masculinization programming window, but not the late window, results in compensated Leydig cell failure in adulthood. Note that blood testosterone levels are not different between groups (A), but DBP-MPW rats require significantly higher LH levels (B) to maintain this, resulting in an increase in the LH/log testosterone ratio (C) specifically in the DBP-MPW group; this was evident for rats with scrotal or cryptorchid testes but was more marked for the latter (C). Compensated Leydig cell failure was inversely correlated with anogenital distance (D) and average testis weight (E). (A-C) Values are mean $\pm \mathrm{SEM}$, with analysis by ANOVA with Bonferroni correction $\left({ }^{* *} P<0.01,{ }^{* *} P<0.001\right.$, in comparison to respective control). (D and E) Data were analyzed by linear regression. DBP, dibutyl phthalate; MPW, masculinization programming window; LW, late window.

"dysgenetic" events in fetal life. However, dysgenetic features comparable to those shown in Figure 7 in men with GCNIS were evident in many biopsies from men with low sperm counts, and one example, which includes an extensive focal dysgenetic area, is illustrated in Supplemental Figure 3.

Fetal origin of focal dysgenetic areas in DBP-exposed rats. Focal dysgenetic features in the adult testis, whether in human cases or in DBP-exposed rats, cannot be proved to originate in fetal life, as there is no direct way of following or tracing them over time. Therefore, the approach we took was based on the hypothesis that the focal areas of malformed seminiferous tubules (dysgenetic areas; Figure 6, A and B) in testes of adult rats (DBP exposed) derived from the "focal dysgenetic regions" of aggregated fetal Leydig cells and ectopic Sertoli cells that were induced in fetal life by DBP-MPW exposure (Figures 1 and 2). If this was correct, focal dysgenetic features should be detectable after birth and during the prepubertal period in testes of DBP-MPW-exposed animals. Accordingly, we examined the testes of DBP-MPW-exposed rats at postnatal days (Pnd) 4, 10, 15, and 25 and immunostained for SMA (to delineate seminiferous tubules) and 3 $\beta$-HSD (to identify Leydig cells). As illustrated in Figures 6 and 8, 53\%-83\% of DBP-MPW-exposed rats had one or more dysgenetic foci within their testes at all ages examined, although the size and shape of these regions varied considerably. At Pnd 4, focal dysgenetic areas appeared similar to those in the E21.5 fetal testis (Figure 8A) with aggregated Leydig cells (compare Figure 8, A-C). However, unlike the fetal testes in which isolated ectopic Sertoli cells were present (see Figure 2), in the Pnd 4 testes of DBP-MPW-exposed animals, some degree of cord formation appeared to be taking place within the focal dysgenetic areas, as evidenced by appearance of SMA-immunopositive peritubular myoid cells (Figure 8, B and C); isolated germ cells were also evident in these regions (Figure $8 \mathrm{C}$ ). The formation of foci of abnormally shaped "anastomotic" seminiferous cords/tubules, some of which harbored intratubular 33-HSD-immunopositive (Leydig) cells (Figure 8F, inset; Supplemental Figure 2), was more prominent at later ages (Pnd 10-25; Figure 8, D-F). These focal dysgenetic areas were comparable to those seen in adulthood in DBP-MPW-exposed animals (Figure 6A and Supplemental Figure 1). Focal dysgenetic areas were never observed in the testes of comparably aged control or DBP-LW rats (data not shown). 
A

Occurence of focal dysgenetic regions in relation to treatment and testis position
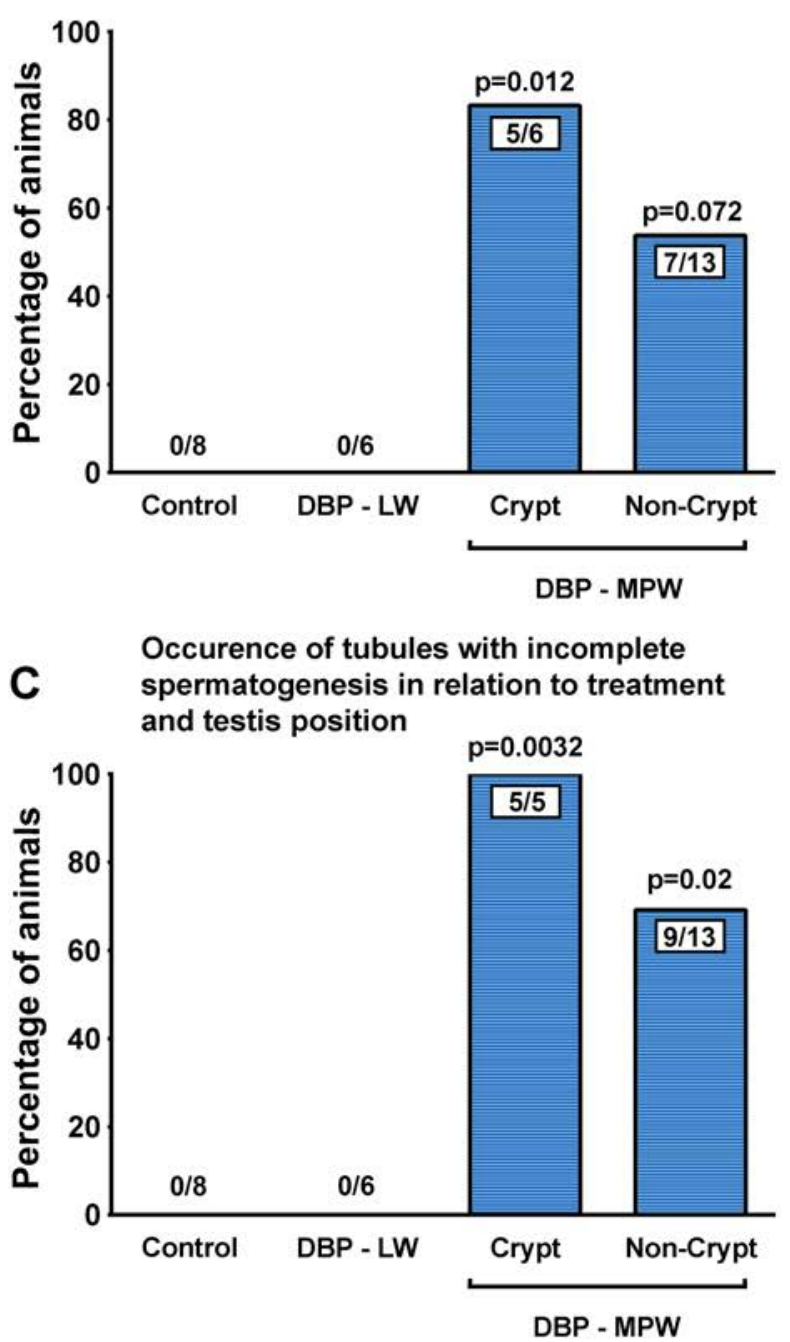

\section{E Occurence of SCO tubules in relation to treatment and testis position}

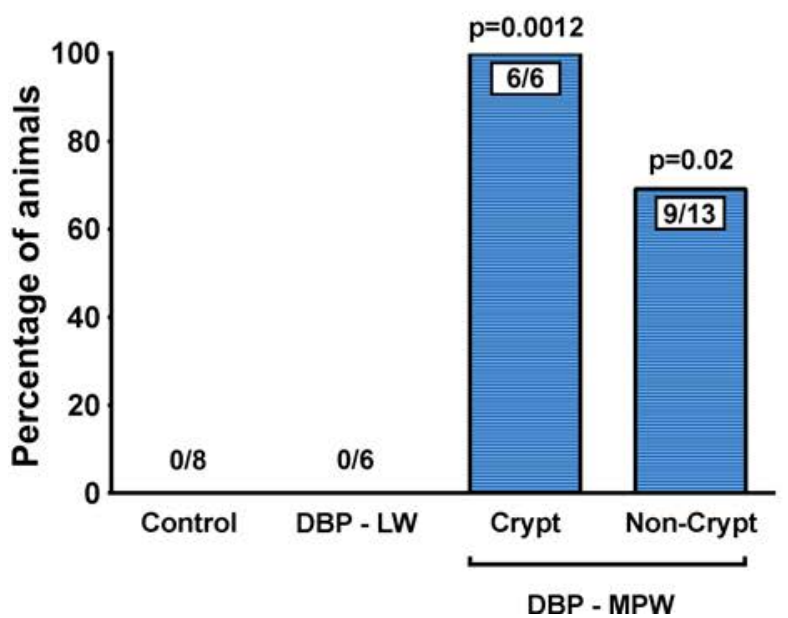

B

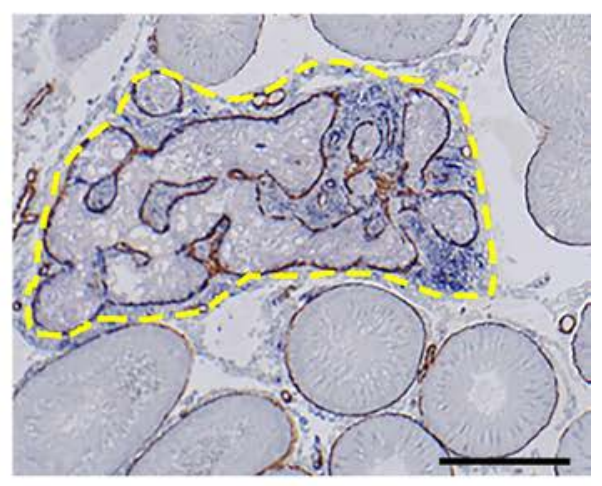

D

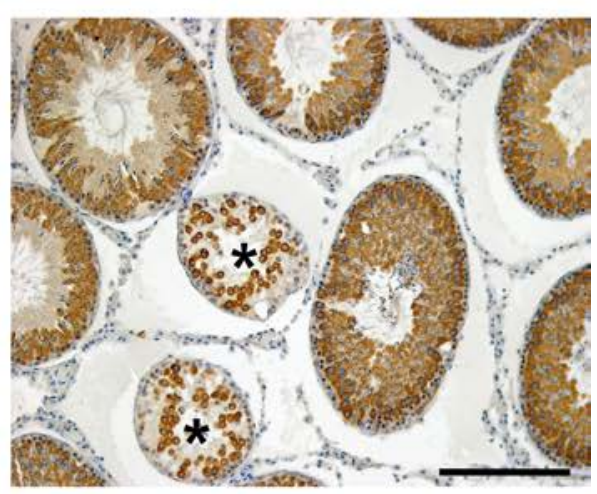

$\mathbf{F}$

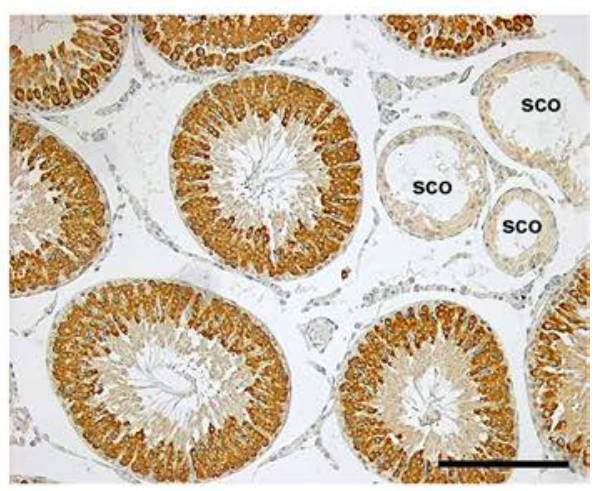

Figure 6. Dibutyl phthalate exposure in the masculinization programming window, but not the late window, increases incidence of focal dysgenesis in the adult testis. Incidence data (left) and examples of the phenotype (right) are shown for focal dysgenetic areas (A and $\mathbf{B}$; highlighted by yellow dashed border in B; brown staining indicates SMA to delineate peritubular myoid cells and blue staining indicates 3 $\beta$-HSD to identify Leydig cells), tubules with incomplete spermatogenesis (C and $\mathbf{D}$; highlighted by asterisk in $\mathbf{D}$; brown staining indicates DAZL to identify germ cells), and Sertoli cell-only (SCO) 
tubules (E and F; brown staining indicates DAZL to identify germ cells). Scale bars: $200 \mu \mathrm{M}$. Note that results for the DBP-MPW group are categorized according to the testicular phenotype. Analysis was by Fisher's exact test with Bonferroni correction. DBP, dibutyl phthalate; MPW, masculinization programming window; LW, late window.

Interrelationship between focal dysgenetic areas and AGD (as an indicator of fetal androgen exposure in the MPW) in rats. To provide insight into the relationship between AGD and focal testicular dysgenesis, we evaluated the correlation between AGD and the number of ectopic Sertoli cells per testis cross section in the fetal E21.5 testis (Figure 2, D and F) or focal dysgenetic areas in the adult testis (Figure 6A). For the latter analysis, the total cross-sectional area of focal dysgenetic regions was measured and expressed as a percentage of the total testis area, based on analysis of two complete cross sections from different regions of the testis of each adult rat. The results showed a significant negative correlation between AGD and focal dysgenesis, irrespective of whether it was measured at E21.5 or in adulthood (Figure 9).

\section{Discussion}

The present studies tested three interrelated hypotheses: first, that the hypothesis concerning human TDS can be verified in an experimental animal model; second, that TDS disorders arise as a consequence of androgen deficiency within the previously identified MPW (ref. 20); and third, that TDS disorders and androgen deficiency (in the MPW) are linked to occurrence of focal dysgenesis. Our results provide robust support for the hypothesis that TDS disorders originate in fetal life and demonstrate that these disorders are only inducible by DBP-induced androgen deficiency in rats when the deficiency occurs specifically within the MPW. DBP induction of comparable fetal androgen deficiency after the MPW does not induce TDS disorders, and neither does more prolonged DBP-induced androgen suppression before, during, and after the MPW (DBP-FW treatment regimen) induce any greater incidence of TDS disorders than treatment just within the MPW; if anything the opposite is the case. We also show that DBP-induced focal dysgenesis, comparable to that found in the testes of some men with TDS disorders, is closely linked in rats to TDS disorders and to the MPW. Therefore, our results provide insights into the mechanistic basis and associations of TDS disorders. They also reaffirm the utility of AGD as a lifelong readout of androgen exposure within the MPW (20), with certain minor caveats $(11,53)$, and as an indicator of risk of TDS disorders and focal dysgenesis.

The TDS hypothesis has focused attention and research effort on reproductive disorders in newborn boys and young men. As some of these disorders are very common and/or may be increasing in incidence $(1,3,7)$, concerns have focused on what might cause this high incidence. If the TDS hypothesis is correct, concern would be focused on factors acting during pregnancy $(3,7)$. The TDS hypothesis cannot be tested by studies in man, because it is not possible to evaluate androgen exposure and fetal testis development and relate this to subsequent disorders evident at birth or to adult-onset disorders, such as low sperm count. The only realistic possibility was to evaluate the TDS hypothesis in an animal model, as in the present studies, and then to assess the relevance of the model findings to man and their fit with the original TDS hypothesis.

Two key findings from the present studies are (a) demonstration of the close interrelationship between DBP-induced focal (histological) dysgenesis in the adult rat testis and occurrence of TDS disorders, such as cryptorchidism, and (b) that a similar interrelationship is evident in fetal life between DBP-induced focal testicular dysgenesis and the degree of suppression of androgen exposure in the MPW, as indicated by AGD. The precise basis for such a link is not obvious because there is no evidence that intratesticular androgen deficiency causes testicular morphological changes, especially when the critical period (MPW) is after completion of testis differentiation and seminiferous cord formation (Figure 10). We suggest that "focal dysgenesis," manifesting as abnormal organization/distribution of testicular somatic cells (e.g., of fetal Leydig and Sertoli cells as shown presently), leads to deficiencies in somatic cell function (e.g., fetal Leydig cell steroidogenesis and immaturity/dysfunction of Sertoli cells that fail to properly support germ cell development), which in turn leads to reduced reproductive organ size and AGD as well as increased incidence of TDS disorders (Figure 10). Hence, the close interrelationship between focal testicular dysgenesis and occurrence/severity of TDS disorders is probably not because one causes the other, but because both share a common origin/cause (Figure 10), consistent with the original TDS hypothesis (6). This is supported by the fact that focal dysgenesis is inversely correlated with AGD in fetal life (this study and ref. 40) and adulthood (this study).

Our results provide both indirect and direct evidence to support the translatability of the present animal model results to humans. Indirect support comes from our demonstration of the robust interrelationship in rats between reduced AGD and occurrence of TDS disorders as well as focal testicular dysgenesis; AGD 
A

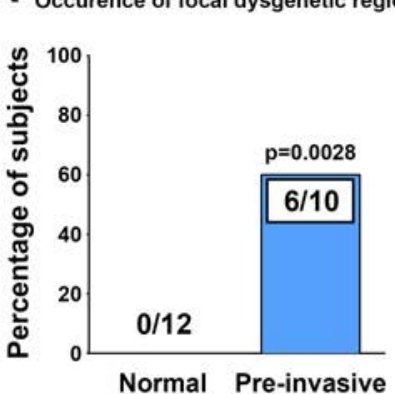

D Occurence of tubules with abnormal spermatogenesis

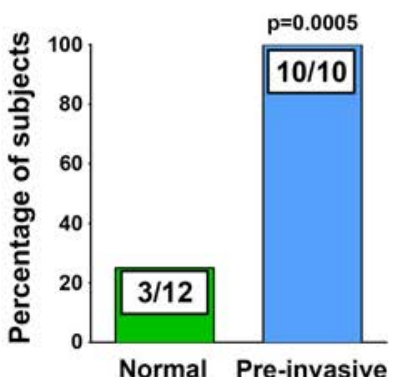

G

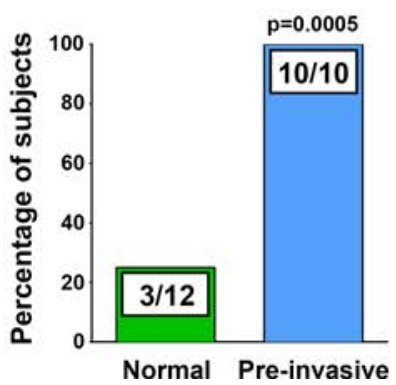

B

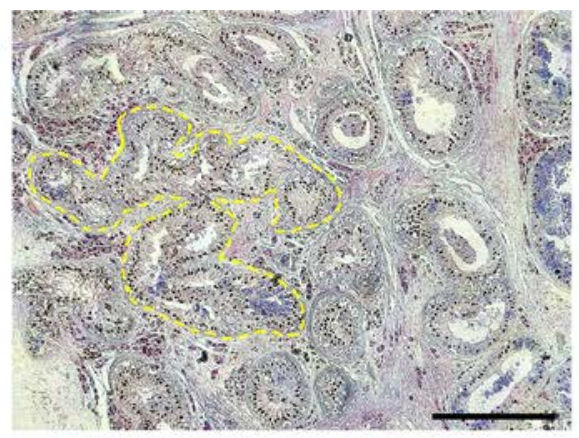

E

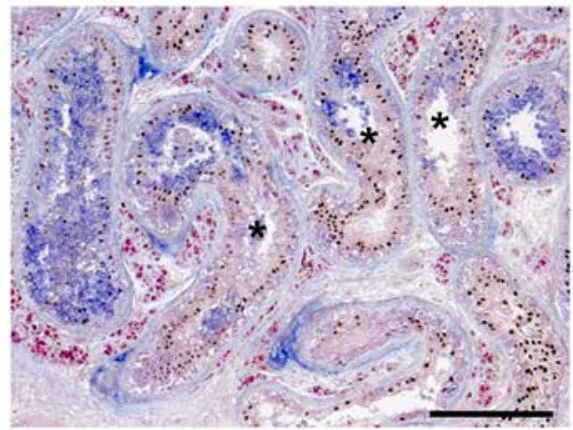

H

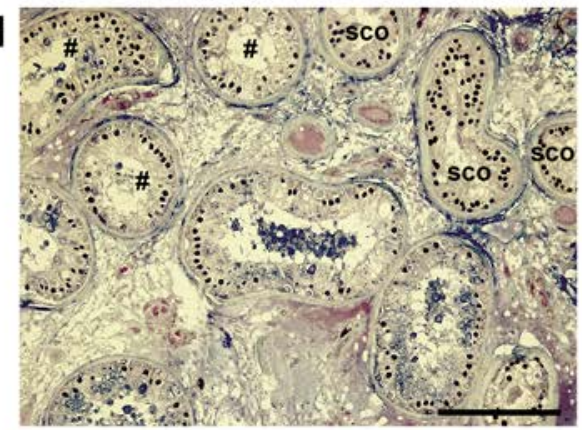

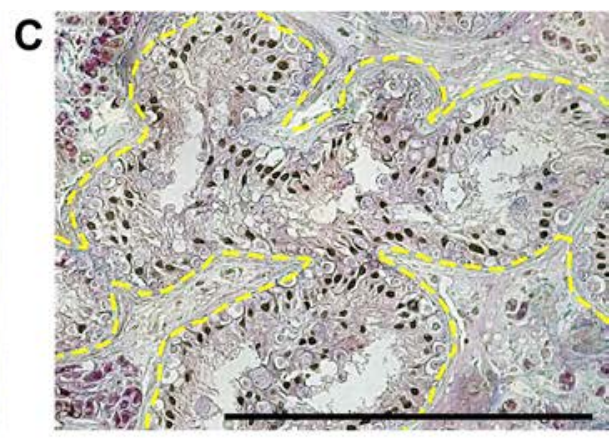

$F$

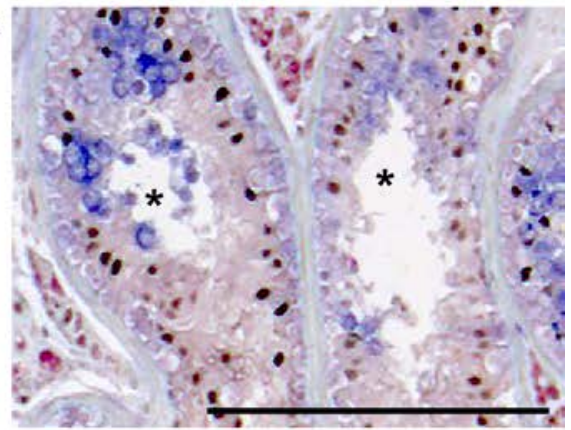

I

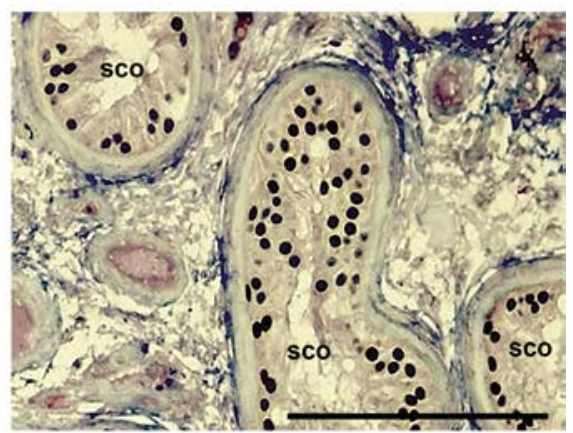

Figure 7. Increased incidence of focal dysgenesis in testes of young men with preinvasive germ cell neoplasia in situ, as exemplars of "human TDS," in comparison to normal controls without germ cell neoplasia in situ. Incidence data (left) and examples of the phenotype (middle and right) are shown for focal dysgenetic areas (A-C; highlighted by yellow dashed border in $\mathbf{B}$ and $\mathbf{C}$ ), tubules with abnormal spermatogenesis ( $\mathbf{D}$ and $\mathbf{E}$; highlighted by asterisks in E and F), and Sertoli cell-only (SCO) tubules (G-I). Scale bars: $100 \mu \mathrm{M}$. For the photographed images, sections were triple immunostained for SOX9 (brown; Sertoli cells), CYP11a1 (red; Leydig cells), and VASA (Blue; germ cells). Tubules containing GCNIS are indicated by pound signs in $\mathbf{H}$. An example of one of the normal controls, immunostained for the same 3 proteins, is shown in Supplemental Figure $\mathbf{3}$. Note that the testis section shown in $\mathbf{H}$ and $\mathbf{I}$ exhibits some nonspecific blue staining in connective tissue/interstitium. Statistical analysis was by Fisher's exact test. GCNIS, germ cell neoplasia in situ.

provides a highly specific readout of androgen exposure within the MPW in rats (this study and ref. 20). As there is already a substantial body of similar association data in human males (Table 1), it is reasonable to propose that an MPW exists in humans, so that studies to identify potential causes of TDS disorders should focus on the presumptive MPW during fetal development. The timing and duration of the MPW in humans is unknown but may be within 8 to 14 weeks' gestation, based on fetal AGD measurements (20). Thus, there is a significant male-female difference in AGD by 11-13 weeks' gestation (54), which is fully developed by $17-20$ weeks $(26,54)$. Moreover, fetal exposure to painkillers, which has been shown to suppress testosterone production by the fetal human testis (55), is associated with reduced AGD in boys (56, 57), and this may be restricted to exposures during 8-14 weeks' gestation (56).

To provide more direct evidence for human relevance of the present experimental rat studies, we showed that similar focal dysgenetic features were evident in testis tissue from young adult men with GCNIS (preinvasive TGCC) similar to that found in testes from adult rats exposed to DBP during the MPW. We chose preinvasive TGCC samples as a human TDS example for two reasons. First, the TDS hypothesis was originally based around TGCC and its fetal origins (6). Second, by studying such tissue 

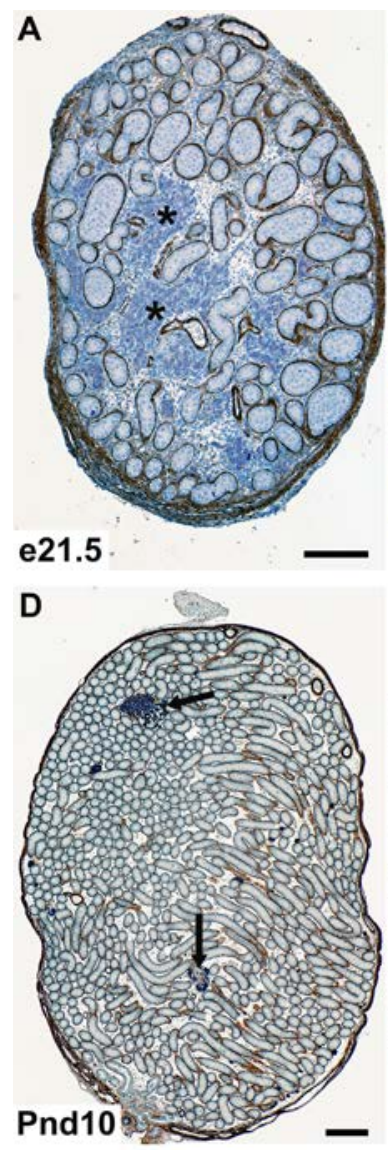
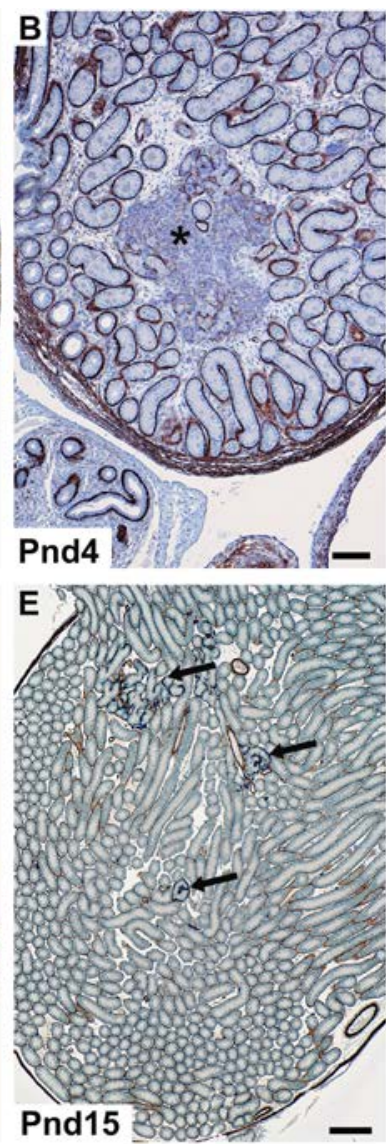
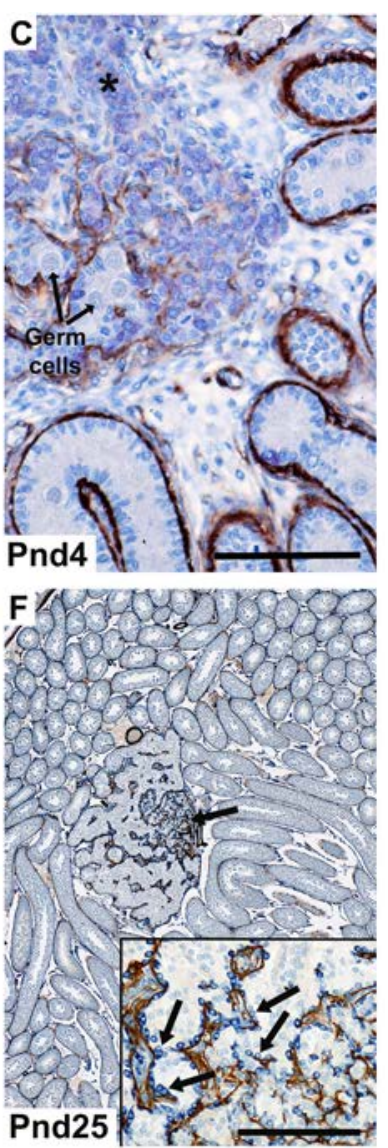

Figure 8. Postnatal evolution of focal dysgenetic areas in testes of rats exposed to dibutyl phthalate in the masculinization programming window. Representative images from animals at E21.5 (A), postnatal day 4 (Pnd 4; $\mathbf{B}$ and $\mathbf{C}$ ), Pnd 10 (D), Pnd 15 (E), and Pnd 25 (F) are shown after immunofluorescence staining for 3 3 -HSD (dark blue; Leydig cells) and smooth muscle actin (brown; peritubular myoid cells and blood vessels) to identify focal areas of abnormal seminiferous cords/tubules. Asterisks in $\mathbf{A}$ and $\mathbf{B}$ show focal aggregation of (fetal) Leydig cells, which also contain ectopic Sertoli cells (see Figure 2). Pnd 4 (B; asterisk = aggregated Leydig cells) is the earliest age when focal formation of abnormally shaped seminiferous cords/tubules becomes evident, but at later ages these are fully developed. Focal dysgenetic areas (black arrows) varied considerably in shape and size and were not found in every animal; an example of their appearance in adulthood is shown in Supplemental Figure 1 and in Figure 6. The inset in $\mathbf{F}$ shows a high-magnification view of part of the focal dysgenetic area to highlight presence of intratubular Leydig cells (arrows). Scale bars: $200 \mu \mathrm{M}$. DBP, dibutyl phthalate; dys, dysgenesis MPW, masculinization programming window.

before formation of an overt tumor, we avoided any potential confounding resulting from the presence of a tumor $(9,18)$. Although men with low sperm counts/infertility are potentially the largest TDS group $(2,3,6-8)$ and testes from some such men also show focal dysgenetic features (this study and ref. 17), it is not possible to prove that such samples have a fetal origin and are definitive "TDS cases," whereas there is general agreement on the fetal origins of GCNIS-TGCC $(3,9)$. No animal model for GCNIS-TGCC exists, including the DBP-MPW model. DBP induces fetal germ cell changes, but these are not specific to the MPW and are not analogous to how GCNIS is considered to originate (58).

The present findings demonstrate that in rats compensated adult Leydig cell failure is a specific consequence of DBP-induced androgen deprivation during the MPW, similar to other established TDS disorders, such as cryptorchidism and hypospadias (Figure 10 and Table 1). This fits with our finding that AGD, which is programmed by androgens during the MPW (20), is negatively correlated with the LH/log testosterone ratio, which defines compensated Leydig cell failure. These observations extend our earlier finding that fetal androgen deprivation, whether via DBP exposure in rats or transgenesis in mice, results in compensated Leydig cell failure in adulthood via an epigenetic change to the stem/progenitor cells for adult Leydig cells (48).

In human males, compensated adult Leydig cell failure can arise for reasons unconnected to fetal life (59), but our experimental rodent findings indicate that, if associated with a TDS disorder, it might have a fetal origin (Figure 10), as also suggested by its association with focal dysgenetic changes in the adult rat (this study) and human testis (17) and with GCNIS (52). In support of this, a recent population-based analysis of $>8,000$ young European men showed that those $(\sim 16 \%)$ with low sperm counts (some cases of which may arise because of TDS) exhibited compensated Leydig cell failure (5). Moreover, men with idiopathic infertility also exhibit compensated Leydig cell failure as a group (49), and some of these may be examples of TDS. In young men, this could mean that the occurrence of a low sperm count plus compensated Leydig cell failure might be indicative of TDS; if this interpretation is correct, such individuals should also have reduced AGD, but this has not yet been investigated. Although we did not measure sperm counts in our rat studies, we showed that testis weight, which is directly related to daily sperm production $(60,61)$, was inversely related to compensated Leydig cell failure. Additionally, our results show that the severity of DBP-MPW-induced compensated 
A e21.5: AGD v ectopic Sertoli cell number

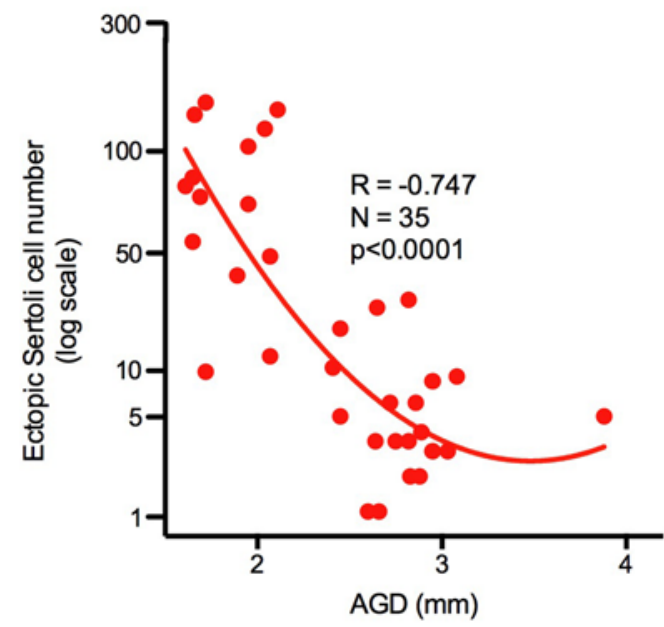

B

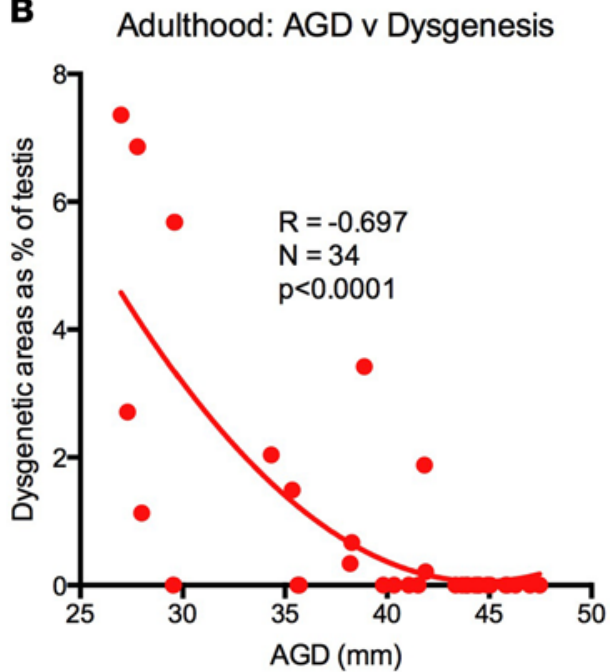

Figure 9. Inverse relationship of anogenital distance to focal dysgenesis induced by dibutyl phthalate exposure during the masculinization programming window. There is an inverse relationship of ACD to focal dysgenesis in the rat testis in fetal life (A; ectopic Sertoli cell number) and in adulthood (B; focal dysgenetic area as percentage of total testis cross-sectional area). Data were analyzed by second order polynomial (quadratic) regression, with statistical significance evaluated via Spearman correlation. The data sets for $\mathbf{A}$ and $\mathbf{B}$ correspond to the animals shown in Figure 2F and Figure 6, respectively. ACD, anogenital distance.

Leydig cell failure is increased in rats with a concomitant TDS disorder (i.e., comparison of rats with descended versus undescended testes), in keeping with our other findings that the more severe the TDS phenotype, the greater the reduction in AGD. More generally, the present experimental studies in rats reinforce the evidence that fetal events play a role in determining adult Leydig cell function and testosterone levels in men (14).

Our animal model has limitations. Although some studies have demonstrated an association between pregnancy exposure to phthalates such as DBP and reduced AGD in sons $(62,63)$, more direct studies in vitro $(64)$ or by xenografting $(65,66)$ have shown no effect of $\mathrm{DBP} /$ phthalate exposure on steroidogenesis by the fetal human testis. However, our studies were not undertaken to evaluate if DBP exposure is a cause of TDS disorders in humans. We used the DBP-exposed rat simply as a model system in which to test whether DBP-induced perturbation of testis cell organization, and resulting focal dysgenesis and fetal Leydig cell

Table 1. Comparability of findings in the present rat model of TDS, with observations in human cases classed as TDS and the evidence linking them to altered fetal androgen exposure in the masculinization programming window, as indicated by anogenital distance

\begin{tabular}{|c|c|c|c|}
\hline TDS parameter & Human evidence & Rat model & Refs. for human studies \\
\hline Cryptorchidism & Associated with reduced ACD & $\begin{array}{l}\text { Associated with reduced ACD } \\
\text { and focal testicular dysgenesis }\end{array}$ & $27-30$ \\
\hline Hypospadias & Associated with reduced AGD & $\begin{array}{l}\text { Associated with reduced AGD } \\
\text { and focal testicular dysgenesis }\end{array}$ & $28,30-33,81$ \\
\hline Low sperm count & Associated with reduced AGDA & $\begin{array}{l}\text { Reduced testis size } \\
\text { (reduced sperm production) } \\
\text { associated with reduced AGD }\end{array}$ & $34-37$ \\
\hline TGCC/GCNISD & $\begin{array}{l}\text { Associated with low sperm count, } \\
\text { cryptorchidism, focal testicular dysgenesis }\end{array}$ & $\begin{array}{l}\text { TGCC/GCNIS does not occur in } \\
\text { this/other animal models }\end{array}$ & $3,6,16,18,51,52$ \\
\hline
\end{tabular}




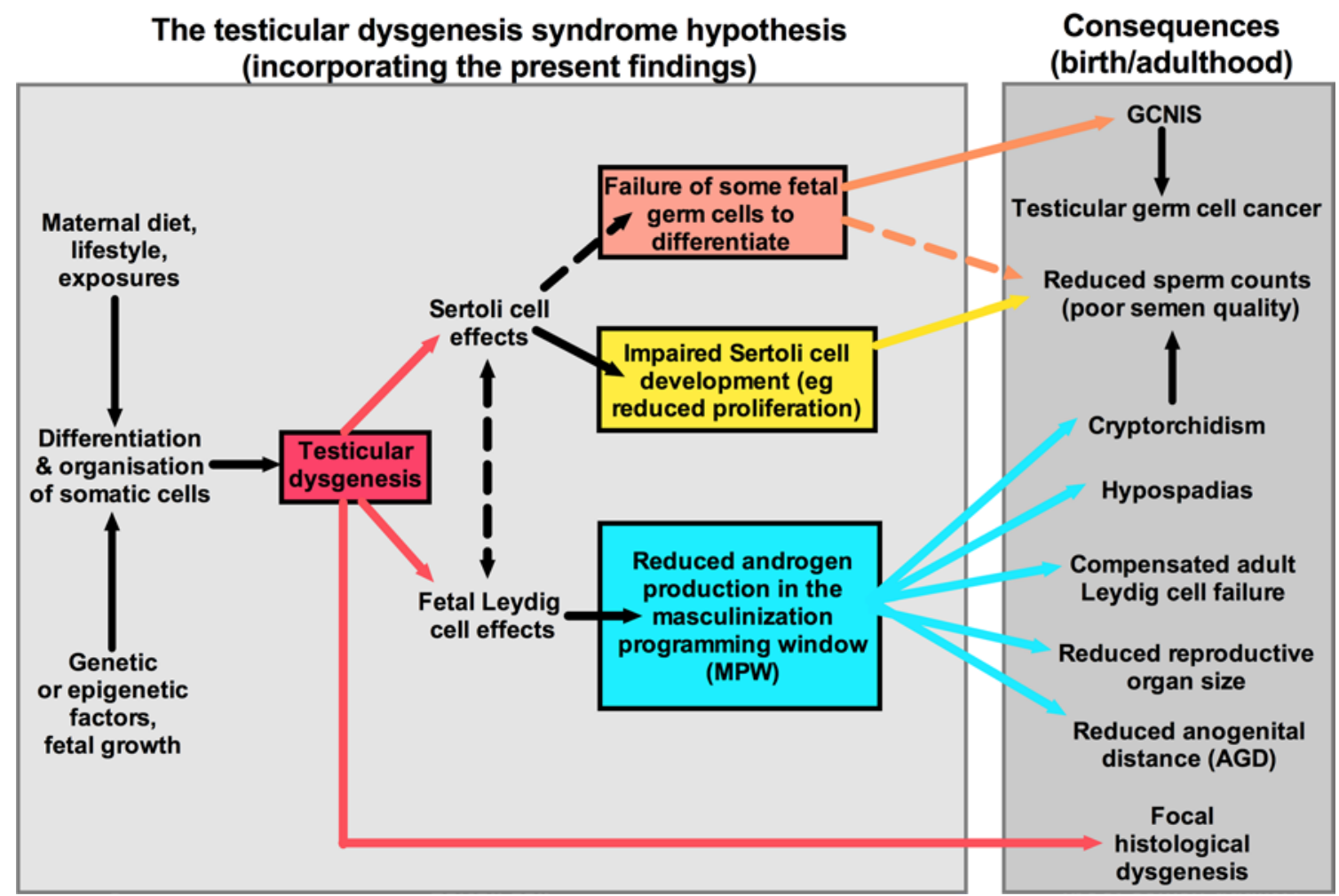

Figure 10. Suggested revision of the testicular dysgenesis syndrome hypothesis, based on incorporation of findings from the present study. GCNIS, germ cell neoplasia in situ.

dysfunction, leads to adult TDS disorders and, if so, whether there is a critical period for such an effect. In this regard, our findings with regard to the consequences of DBP-induced androgen deficiency in the MPW agree completely with findings from other treatments in which deficiency in androgen action has been induced in rats by fetal exposure to androgen receptor antagonists $(20,22,23,67-69)$ or to $5 \alpha$-reductase inhibitors $(67,68)$ during the period now established as the MPW, and such treatments are therapeutic antiandrogens in humans. Therefore, we consider our findings conceptually relevant to humans, even if the factors that might induce focal dysgenesis and resulting TDS prove to be different in humans versus rats (70).

In providing animal model validation of the TDS hypothesis, our results have important human health implications, in view of the high, and possibly increasing, prevalence of TDS disorders in young men (6). Induction of focal testicular dysgenesis, and consequent increased risk of TDS, can have multiple potential causes, ranging from genetic to environmental/lifestyle exposures $(3,6,9,51)$, although the precise causal factors remain largely unknown. The present studies provide an important step forward in basic understanding by highlighting the key importance of androgen deficiency in the MPW as the underlying mechanistic cause of later TDS disorders and associated reduction in AGD in rats. As there is already a substantial body of similar association data in human males (Table 1), it is reasonable to propose that an MPW exists in humans, so that studies to identify potential causes of TDS disorders should focus on the presumptive MPW ( 8-14 weeks' gestation). While such studies have several inherent limitations, the measurement of AGD in newborn offspring, as an indicator of androgen exposure within the presumptive MPW, will play an important role, even if interindividual variation may restrict its usefulness to population-based studies $(11,25,36)$.

\section{Methods}

Human testis tissue. The tissue specimens were fixed overnight in $4 \%$ buffered formalin or modified Stieve's fixative. The focus of the present studies was on men classed as having TDS, and, as the most definitive example of TDS is men diagnosed with TGCC or its preinvasive stage GCNIS $(6,9)$, the latter group was the present focus. For assessment of preinvasive TGCC, fragments of orchiectomy specimens with GCNIS, $(n=10)$ were used. All samples were assessed by an experienced pathologist using a panel of 
immunohistochemical markers to characterize the presence of preinvasive GCNIS cells. It is emphasized that this group of men is highly selective but constitutes the group of men on which the original TDS hypothesis was founded (6). Access to control "normal" human testis tissue from young adult men comparable in age to the GCNIS group is limited for ethical reasons. We used two groups of samples as controls. The first group $(n=8)$ comprised biopsies obtained from the "normal" testis of men who had been diagnosed with TGCC in the contralateral testis. In Denmark, all such men diagnosed with TGCC are routinely offered a biopsy of the contralateral testis to determine if GCNIS is present (71); we used biopsies that were negative for GCNIS. The second group $(n=4)$ comprised men with symptoms of testicular pain but no evidence for any testicular abnormality after orchiectomy.

Animals and treatments. Wistar rats (Harlan) were housed for a minimum of 2 weeks prior to use in experimental studies and had free access to sterile water and a soy-free breeding diet [RM3(E); SDS]. Housing conditions were: lights, 07:00-19:00 hours; temperature, $19^{\circ} \mathrm{C}-21^{\circ} \mathrm{C}$; humidity, $45 \%-65 \%$; and GOLD shavings and LITASPEN standard bedding (SPPS). Time-mated females were allocated randomly to receive vehicle control treatment or $750 \mathrm{mg} / \mathrm{kg}$ DBP (Sigma-Aldrich; $99 \%$ pure according to the supplier) in $1 \mathrm{ml} / \mathrm{kg}$ corn oil daily by oral gavage. The dose of DBP was chosen as it induces a high incidence of focal dysgenesis as well as profoundly suppressing testosterone production by fetal Leydig cells (40). Three DBP treatment groups were used in this study: DBP-FW (E13.5-E21.5), DBP-MPW (E15.5-E18.5), and DBP-LW (E19.5-E21.5). All treatments were administered between 09:00-10:30 hours in a single animal facility at the University of Edinburgh. No generalized adverse effects of the DBP treatments were observed in exposed females, and litter size and sex ratio were unaffected by treatment. Male fetuses were collected at E17.5 (within the MPW), E21.5 (end of LW), or at Pnd 4, 10, 15, 25, or 90 (adulthood). Animal numbers/litters used varied between experiments but always involved at least 3 litters and usually more than 5; for studies of the adult phenotype of DBP-MPW offspring, 11 litters were used. Pregnant dams were killed by $\mathrm{CO}_{2}$ inhalation followed by cervical dislocation. Fetuses were removed, decapitated, and placed in ice-cold PBS (Sigma-Aldrich). Postnatal animals were housed with their natural mothers from birth until weaning or in cages with a maximum of 6 animals after weaning and were killed by cervical dislocation. Fetal testes were microdissected and fixed in Bouin's fixative for 1 hour, while postnatal testes were fixed in Bouin's fixative for 3 hours (Pnd 4-25) or 6 hours (adults) and then transferred to $70 \%$ (v/v) ethanol before processing into paraffin blocks by standard procedures. Fetal testes used for ITT measurements were snap frozen on dry ice.

Adult reproductive phenotype analysis. Bodyweight was measured and then AGD was measured using digital callipers (Faithfull Tools). Animals were then subjected to a thorough inspection to determine testicular descent and the normality of the penis. Hypospadias was classified as mild (glanular), moderate, or severe (20-22); severe cases were all perineal and included exposure of the penile os bone. The penis was then carefully dissected out, its length was determined using digital callipers, and it was weighed (20-23). Initial classification of cryptorchidism was based on the absence of one or both testes from the scrotum and an inability to manipulate the relevant testis into the scrotum. This preliminary diagnosis was confirmed after opening of the abdomen, when the position of cryptorchid testes was further defined as high abdominal (located adjacent to the kidney) or mid to lower abdominal. The presence or absence of the gubernacular ligament was recorded and, if present, whether it was normal and short or thin and abnormally elongated ( $>5$ times normal). Some high scrotal testes were classified as inguinal when the gubernaculum was found to be absent/elongated, as it was considered that these testes could not be consistently anchored in the scrotum; these testes were always intermediate in size between normal scrotal testes and fully cryptorchid testes. The testes and prostate were dissected out and weighed for each animal, and both testes were fixed in Bouin's as described above.

Triple immunofluorescence for SMA, 3B-HSD, and SOX-9 in rats. To visualize focal dysgenesis and ectopic Sertoli cells, specific antibodies were used for coimmunolocalization of 3 $\beta$-HSD (Leydig cell marker; Santa Cruz, catalog SC-30820), SOX-9 (Sertoli cell marker; Chemicon International, catalog AB5535), and a-SMA (peritubular myoid cell marker; Sigma-Aldrich, catalog A2547). Slides were washed in between all incubation steps in TBS ( 3 times for 5 minutes each), and all incubations were carried out in a humidity box (Fisher Scientific). Sections were dewaxed and rehydrated using standard procedures, followed by a peroxidase block in $3 \%(\mathrm{v} / \mathrm{v}) \mathrm{H}_{2} \mathrm{O}_{2}$ in methanol for 30 minutes. Next, the sections were blocked in normal chicken serum (NCS; Biosera) diluted 1:5 in TBS containing 5\% (w/v) BSA (NCS/TBS/BSA), followed by incubation with anti-SOX-9 antibody diluted 1:5,000 in NCS/TBS/BSA overnight at $4^{\circ} \mathrm{C}$. The next day, sections were incubated with peroxidase-conjugated chicken anti-rabbit secondary antibody (Santa Cruz, 
catalog SC-2963), diluted 1:200 in NCS/TBS/BSA for 30 minutes at room temperature, followed by incubation with Tyr-Cy3 (Perkin Elmer-TSA-Plus Cyanine3 System; Perkin Elmer Life Sciences) according to the manufacturer's instructions. Before the next primary antibody dilution was added, the sections were subjected to antigen retrieval by boiling in a pressure cooker in $0.01 \mathrm{~mol} / 1$ citrate buffer ( $\mathrm{pH}$ 6.0) for 5 minutes, before being left to cool for 20 minutes. This was followed by another block in NCS/TBS/BSA and overnight incubation at $4^{\circ} \mathrm{C}$ with anti-3 $\beta$-HSD antibody diluted 1:6,000 in NCS/TBS/BSA. On the third day, slides were incubated with peroxidase-conjugated chicken anti-goat secondary antibody (Santa Cruz, catalog SC-2961) diluted 1:200 in NCS/TBS/BSA for 30 minutes at room temperature, followed by incubation with Tyr-fl (Perkin Elmer-TSA-Plus Fluorescein System; Perkin Elmer Life Sciences) according to the manufacturer's instructions. Sections were again blocked against peroxidase in $3 \%(\mathrm{v} / \mathrm{v}) \mathrm{H}_{2} \mathrm{O}_{2}$ in TBS plus $0.01 \%$ (v/v) Tween-20 (Sigma-Aldrich) for 20 minutes, followed by blocking in NCS/TBS/BSA and incubation with anti-SMA antibody diluted 1:10,000 in NCS/TBS/BSA for 1 hour at room temperature. Sections were then incubated with peroxidase-conjugated chicken anti-mouse secondary antibody (Santa Cruz, cata$\log$ SC-2962), diluted 1:200 in NCS/TBS/BSA for 30 minutes at room temperature, followed by incubation with Tyr-Cy5 (Perkin Elmer-TSA-Plus Cyanine5 System; Perkin Elmer Life Sciences) according to the manufacturer's instructions. Finally, slides were mounted with Permafluor (Thermo Scientific), and fluorescent images were captured using a Zeiss LSM 710 Axio Observer Z1 confocal laser microscope (Carl Zeiss Ltd).

Identification and quantification of focal dysgenetic areas in rats. For the purposes of the present studies, focal dysgenetic areas in rats were classified using different criteria in fetal life than postnatally, as explained in Results. Thus, in E17.5 and E21.5 fetal testes, identification was based on the number of ectopic Sertoli cells, which were determined as follows. Testes from the different age and treatment groups ( $n=3-15$ from 3-5 litters per treatment group) were serial sectioned, and 3 sections were chosen, corresponding to approximately $25 \%, 50 \%$, and $75 \%$ intervals through the serially sectioned testis; these were triple immunostained for $\alpha$-SMA, 3 $\beta$-HSD, and SOX-9, as above. Whole testis confocal scanned images were recorded and used to count all SOX-9-positive (Sertoli) cells per testis cross section that were located in the interstitium and outside of seminiferous cords (ectopic Sertoli cells), and the total number per testis was determined. In early postnatal and adult rat testes, focal dysgenetic areas were visualized by double immunostaining for $\alpha$ - SMA (Sigma-Aldrich) and 3 $\beta$-HSD (Santa Cruz) as described elsewhere (72) to delineate seminiferous cords/tubules from the interstitial compartment. Any focal area in the testis that exhibited grossly misshapen seminiferous tubules was classed as a focal dysgenetic area; these varied considerably in shape and size but were generally more extensive and bizarre in cryptorchid than in noncryptorchid testes (see Supplemental Figure 1). All focal dysgenetic areas occurred in central regions of the testis. To determine the percentage volume of focal dysgenetic areas per testis, two complete cross sections per testis were analyzed using a Zeiss Axio-Imager microscope (Carl Zeiss Ltd.) fitted with a Hitachi HVC20 camera (Hitachi Denshi Europe) and a Prior automatic stage (Prior Scientific Instruments Ltd.). Image-Pro 6.2 with Stereologer plug-in software (Mag-Worldwide) was used to draw around the complete testis cross section and focal dysgenetic areas to determine their areas; percentage focal dysgenesis was then computed as the ratio of the latter to the former $\times 100$.

Identification of tubules with incomplete spermatogenesis or SCO in rats. To visualize germ cells and thus to identify SCO tubules and tubules with incomplete spermatogenesis in adult rat testes, sections were immunostained with an antibody to detect the germ cell marker DAZL (gift from H. Cooke, University of Edinburgh; 1:1,000), using standard immunohistochemistry techniques as described elsewhere (73). Two complete cross sections of each adult testis were then systematically evaluated by a person blinded to the treatment group who identified any tubules with incomplete spermatogenesis (i.e., tubules lacking specific germ cell types that should be present, tubules with clearly reduced germ cell numbers, or tubules with no germ cells [SCO]); note that SCO tubules located at the testis periphery were ignored, as these are likely to be a normal part of the rete testis. Any animal exhibiting any tubule with incomplete spermatogenesis or SCO was classified as having this dysgenetic feature, although it is emphasized that where such tubules were present they were usually quite numerous.

Identification and quantification of focal dysgenetic features in the human adult testis. Using methods similar to those in the rat above, triple immunostaining for SOX-9 (Sertoli cells; Chemicon, catalog AB5535, 1:200), CYP11a1 (Leydig cells; Sigma-Aldrich, 1:50), and VASA (germ cells; Abcam, catalog AB13840, 1:80) was used to delineate cell types for analysis, using methods and antibodies validated previously $(47,48,55,74)$. Sections were blocked using 20\% normal goat serum (v/v) (Biosera) and 5\% BSA (w/v) (Sigma-Aldrich) in TBS. Secondary antibodies were diluted 1:500 in sera, and slides were incubated for 30 minutes with Streptavidin-alkaline 
phosphatase (Vector) at 1:200 in TBS. Fast blue and red were used for protein detection (Perma Blue/Red, Diagnostic BioSystems), followed by antigen retrieval for 2.5 minutes on medium heat. Sections were reblocked in serum/TBS/BSA as above before application of (second) primary antibody, followed by repetition of the above. Streptavidin-horseradish peroxidase (Dako) at 1:500 in TBS was used for detection of 3,3-diaminobenzidine tetrahydrochloride (Dako). Slides were mounted with Permafluor (Thermo Scientific). Each immunohistochemistry run included negative controls for each primary antibody. Immunostained testis cross sections were evaluated in a similar fashion to the rat, as described above. Each testis cross section was characterized for (a) focal areas of dysgenesis, (b) normality or not of spermatogenesis per tubule, and (c) SCO tubules (SOX9-only staining and absence of GC morphology), using approaches comparable to those described above for the rat. Where dysgenetic features ( $b$ and $c$ ) were observed, their relative occurrence was determined in relation to the number of tubules with normal spermatogenesis in the same testis sample; the number of seminiferous tubules evaluated ranged from 94 to 221 in normal controls and 111 to 390 in preinvasive GCNIS samples.

Rat hormone measurements. Testosterone levels in plasma from adult rats were subjected to organic extraction and subsequent hormone measurement by an ELISA assay adapted from an earlier, established radioimmunoassay using methods outlined previously $(75,76)$; the same assay was used to measure fetal ITT, as described by Mahood et al. (50). This assay has been used extensively for the robust measurement of testosterone in biological media from rats (75), mice (77), monkeys (76), and sheep (78) of both sexes; plasma samples from castrate adult rats show values below the assay limit of detection ( $40 \mathrm{pg} / \mathrm{sample}$ for the current studies). Plasma LH was measured by an established radioimmunoassay as outlined previously (79). All samples from each experiment were run in a single assay, and the within-assay coefficients of variation were all $<10 \%$.

Statistics. Values are expressed as mean \pm SEM. Comparison of treatment effects used 1-way ANOVA, followed by Bonferroni correction when multiple treatment groups were being compared, or 2-tailed Student's $t$ test for comparisons between two groups. Incidence data were analyzed using Fisher's exact test, followed by Bonferroni correction when multiple endpoints were being evaluated. Linear regression analysis was used to determine the relationship between AGD and reproductive organ and hormone parameters, but second order polynomial (quadratic) regression, with statistical significance evaluated via Spearman correlation, was used to evaluate the relationship between AGD and focal dysgenesis. Data were log transformed prior to analysis if they were not normally distributed, as was the case for plasma testosterone levels. The analyses used GraphPad Prism (version 6; GraphPad Software Inc.). A P value of less than 0.05 was considered significant. The presented data used each animal as the unit, rather than the litter, because the basis of the present studies was to evaluate the interrelationships between treatment effects on AGD, ITT, plasma testosterone and LH, dysgenesis, and adult phenotype at the individual level.

Study approval. The animals used in this study were treated humanely and according to the Animal (Scientific Procedures) Act 1986 (http://www.legislation.gov.uk/ukpga/1986/14/contents) under project license (PPL 60/4564) approval by the UK Home Office. Studies were conducted following review by the University of Edinburgh Animal Research Ethics Committee.

Adult human testicular biopsies or testis tissue from orchiectomy were obtained from the Western General Hospital, Edinburgh, and from samples stored in the tissue archives of Copenhagen University Hospital. Ethical approval was obtained by the East of Scotland Research Ethics Committee (REC reference - 15/ES/0094) and the regional Committee for Medical Research Ethics in Denmark (permit numbers KF-01 265848 and H-1-2012- 007).

\section{Author contributions}

SVDD, KRK, and RMS designed the studies. SVDD, KRK, RMS, and DR undertook the animal studies, and these authors as well as IW, AB, CMK, and SM undertook the tissue immunostaining, tissue analyses, and hormone measurements. AJ, ERDM, and NES contributed human tissue materials and their analysis and obtained ethical approval, as did RM, RD, and CJS. SVDD, KRK, RM, AJ, ERDM, NES, and RMS wrote the manuscript.

\section{Acknowledgments}

This work was supported by grant G1100358 (to RMS) from the UK Medical Research Council and was undertaken in the MRC Centre for Reproductive Health, which is funded by MRC Centre grant MR/ N022556/1. We thank William Mungall for assistance with the animal work. 
Address correspondence to: Richard M. Sharpe, MRC Centre for Reproductive Health, The Queen's Medical Research Institute, University of Edinburgh, 47 Little France Crescent, Edinburgh EH16 4TJ, United Kingdom. Phone: 44.131.242.6387; E-mail: r.sharpe@ed.ac.uk.

SVDD's present address is: Centre for Integrative Physiology, Biomedical Sciences, Hugh Robson Building, University of Edinburgh, Edinburgh, United Kingdom.

1. Andersson AM, et al. Adverse trends in male reproductive health: we may have reached a crucial 'tipping point'. Int J Androl. 2008;31(2):74-80

2. Sharpe RM. Sperm counts and fertility in men: a rocky road ahead. Science \& Society Series on Sex and Science. EMBO Rep. 2012;13(5):398-403.

3. Skakkebaek NE, et al. Male Reproductive Disorders and Fertility Trends: Influences of Environment and Genetic Susceptibility. Physiol Rev. 2016;96(1):55-97.

4. Jørgensen N, Asklund C, Carlsen E, Skakkebaek NE. Coordinated European investigations of semen quality: results from studies of Scandinavian young men is a matter of concern. Int J Androl. 2006;29(1):54-61; discussion 105.

5. Jørgensen N, et al. Compensated reduction in Leydig cell function is associated with lower semen quality variables: a study of 8182 European young men. Hum Reprod. 2016;31(5):947-957.

6. Skakkebaek NE, Rajpert-De Meyts E, Main KM. Testicular dysgenesis syndrome: an increasingly common developmental disorder with environmental aspects. Hum Reprod. 2001;16(5):972-978.

7. Juul A, et al. Possible fetal determinants of male infertility. Nat Rev Endocrinol. 2014;10(9):553-562.

8. Sharpe RM, Skakkebaek NE. Testicular dysgenesis syndrome: mechanistic insights and potential new downstream effects. Fertil Steril. 2008;89(2 Suppl):e33-e38.

9. Rajpert-De Meyts E. Developmental model for the pathogenesis of testicular carcinoma in situ: genetic and environmental aspects. Hum Reprod Update. 2006;12(3):303-323.

10. Ulbright TM, et al. Germ cell tumours. In: Moch H, Humphrey PA, Reuter VE, Ulbright TM, eds. WHO Classification of Tumours of the Urinary System and Male Genital Organs. 4th Edition. Geneva, Switerland:IARC Press; 2016:189-226.

11. Dean A, Sharpe RM. Clinical review: Anogenital distance or digit length ratio as measures of fetal androgen exposure: relationship to male reproductive development and its disorders. J Clin Endocrinol Metab. 2013;98(6):2230-2238.

12. Akre O, Richiardi L. Does a testicular dysgenesis syndrome exist? Hum Reprod. 2009;24(9):2053-2060.

13. Thorup J, et al. What is new in cryptorchidism and hypospadias--a critical review on the testicular dysgenesis hypothesis. $J$ Pediatr Surg. 2010;45(10):2074-2086.

14. Vanbillemont G, et al. Birth weight in relation to sex steroid status and body composition in young healthy male siblings. J Clin Endocrinol Metab. 2010;95(4):1587-1594.

15. Hart RJ, et al. Early Life Events Predict Adult Testicular Function; Data Derived From the Western Australian (Raine) Birth Cohort. J Clin Endocrinol Metab. 2016;101(9):3333-3344.

16. Hoei-Hansen CE, Holm M, Rajpert-De Meyts E, Skakkebaek NE. Histological evidence of testicular dysgenesis in contralateral biopsies from 218 patients with testicular germ cell cancer. J Pathol. 2003;200(3):370-374.

17. Holm M, Rajpert-De Meyts E, Andersson AM, Skakkebaek NE. Leydig cell micronodules are a common finding in testicular biopsies from men with impaired spermatogenesis and are associated with decreased testosterone/LH ratio. J Pathol. 2003;199(3):378-386.

18. Rajpert-De Meyts E, Almstrup K, Skakkebaek NE. Testicular dysgenesis syndrome and carcinoma in situ testis. In: Jezek D, eds. Atlas of the Human Testis. London, United Kingdom; Springer-Verlag, London; 2008;159-178.

19. Mohnach L, Fechner PY, Keegan CE. Nonsyndromic disorders of testis development. https://www.ncbi.nlm.nih.gov/books/ NBK1547/. Updated June 2, 2016. Accessed February 24, 2017.

20. Welsh $\mathrm{M}$, et al. Identification in rats of a programming window for reproductive tract masculinization, disruption of which leads to hypospadias and cryptorchidism. J Clin Invest. 2008;118(4):1479-1490.

21. Drake AJ, van den Driesche S, Scott HM, Hutchison GR, Seckl JR, Sharpe RM. Glucocorticoids amplify dibutyl phthalate-induced disruption of testosterone production and male reproductive development. Endocrinology. 2009;150(11):5055-5064.

22. Macleod DJ, et al. Androgen action in the masculinization programming window and development of male reproductive organs. Int J Androl. 2010;33(2):279-287.

23. van den Driesche S, Scott HM, MacLeod DJ, Fisken M, Walker M, Sharpe RM. Relative importance of prenatal and postnatal androgen action in determining growth of the penis and anogenital distance in the rat before, during and after puberty. Int $J$ Androl. 2011;34(6 Pt 2):e578-e586.

24. Thankamony A, Ong KK, Dunger DB, Acerini CL, Hughes IA. Anogenital distance from birth to 2 years: a population study Environ Health Perspect. 2009;117(11):1786-1790.

25. Thankamony A, Pasterski V, Ong KK, Acerini CL, Hughes IA. Anogenital distance as a marker of androgen exposure in humans. Andrology. 2016;4(4):616-625.

26. Gilboa Y, Kivilevitch Z, Oren M, Cohen YP, Katorza E, Achiron R. Anogenital distance in male and female fetuses at 20 to 35 weeks of gestation: centile charts and reference ranges. Prenat Diagn. 2014;34(10):946-951.

27. Jain VG, Singal AK. Shorter anogenital distance correlates with undescended testis: a detailed genital anthropometric analysis in human newborns. Hum Reprod. 2013;28(9):2343-2349.

28. Thankamony A, et al. Anogenital distance and penile length in infants with hypospadias or cryptorchidism: comparison with normative data. Environ Health Perspect. 2014;122(2):207-211.

29. Jiang DP, et al. Relationship between anogenital distance and cryptorchidism in human newborns. Zhonghua Nan Ke Xue. 
2015;21(5):432-435.

30. Hsieh MH, Breyer BN, Eisenberg ML, Baskin LS. Associations among hypospadias, cryptorchidism, anogenital distance, and endocrine disruption. Curr Urol Rep. 2008;9(2):137-142.

31. Hsieh MH, Eisenberg ML, Hittelman AB, Wilson JM, Tasian GE, Baskin LS. Caucasian male infants and boys with hypospadias exhibit reduced anogenital distance. Hum Reprod. 2012;27(6):1577-1580.

32. Singal AK, Jain VG, Gazali Z, Shekhawat P. Shorter anogenital distance correlates with the severity of hypospadias in pre-pubertal boys. Hum Reprod. 2016;31(7):1406-1410.

33. Gilboa Y, Perlman S, Kivilevitch Z, Messing B, Achiron R. Prenatal Anogenital Distance Is Shorter in Fetuses With Hypospadias. J Ultrasound Med. 2017;36(1):175-182.

34. Mendiola J, Stahlhut RW, Jørgensen N, Liu F, Swan SH. Shorter anogenital distance predicts poorer semen quality in young men in Rochester, New York. Environ Health Perspect. 2011;119(7):958-963.

35. Eisenberg ML, Hsieh MH, Walters RC, Krasnow R, Lipshultz LI. The relationship between anogenital distance, fatherhood, and fertility in adult men. PLoS One. 2011;6(5):e18973.

36. Eisenberg ML, Lipshultz LI. Anogenital distance as a measure of human male fertility. J Assist Reprod Genet. 2015;32(3):479-484.

37. Mendiola J, Melgarejo M, Moñino-García M, Cutillas-Tolín A, Noguera-Velasco JA, Torres-Cantero AM. Is anogenital distance associated with semen quality in male partners of subfertile couples? Andrology. 2015;3(4):672-676.

38. Eisenberg ML, Jensen TK, Walters RC, Skakkebaek NE, Lipshultz LI. The relationship between anogenital distance and reproductive hormone levels in adult men. $J$ Urol. 2012;187(2):594-598.

39. Zhou N, et al. Anogenital distance is associated with serum reproductive hormones, but not with semen quality in young men Hum Reprod. 2016;31(5):958-967.

40. van den Driesche S, Kolovos P, Platts S, Drake AJ, Sharpe RM. Inter-relationship between testicular dysgenesis and Leydig cell function in the masculinization programming window in the rat. PLoS One. 2012;7(1):e30111.

41. Fisher JS, Macpherson S, Marchetti N, Sharpe RM. Human 'testicular dysgenesis syndrome': a possible model using in-utero exposure of the rat to dibutyl phthalate. Hum Reprod. 2003;18(7):1383-1394.

42. Barlow NJ, McIntyre BS, Foster PM. Male reproductive tract lesions at 6, 12, and 18 months of age following in utero exposure to di(n-butyl) phthalate. Toxicol Pathol. 2004;32(1):79-90.

43. Thompson CJ, Ross SM, Gaido KW. Di(n-butyl) phthalate impairs cholesterol transport and steroidogenesis in the fetal rat testis through a rapid and reversible mechanism. Endocrinology. 2004;145(3):1227-1237.

44. Plummer S, Sharpe RM, Hallmark N, Mahood IK, Elcombe C. Time-dependent and compartment-specific effects of in utero exposure to Di(n-butyl) phthalate on gene/protein expression in the fetal rat testis as revealed by transcription profiling and laser capture microdissection. Toxicol Sci. 2007;97(2):520-532.

45. Habert R, et al. Concerns about the widespread use of rodent models for human risk assessments of endocrine disruptors. Reproduction. 2014;147(4):R119-R129.

46. Parks LG, et al. The plasticizer diethylhexyl phthalate induces malformations by decreasing fetal testosterone synthesis during sexual differentiation in the male rat. Toxicol Sci. 2000;58(2):339-349.

47. van den Driesche S, et al. Proposed role for COUP-TFII in regulating fetal Leydig cell steroidogenesis, perturbation of which leads to masculinization disorders in rodents. PLoS ONE. 2012;7(5):e37064.

48. Kilcoyne KR, et al. Fetal programming of adult Leydig cell function by androgenic effects on stem/progenitor cells. Proc Natl Acad Sci USA. 2014;111(18):E1924-E1932.

49. Andersson AM, Jørgensen N, Frydelund-Larsen L, Rajpert-De Meyts E, Skakkebaek NE. Impaired Leydig cell function in infertile men: a study of 357 idiopathic infertile men and 318 proven fertile controls. J Clin Endocrinol Metab. 2004;89(7):3161-3167.

50. Mahood IK, Hallmark N, McKinnell C, Walker M, Fisher JS, Sharpe RM. Abnormal Leydig Cell aggregation in the fetal testis of rats exposed to di (n-butyl) phthalate and its possible role in testicular dysgenesis. Endocrinology. 2005;146(2):613-623.

51. Jørgensen A, Lindhardt Johansen M, Juul A, Skakkebaek NE, Main KM, Rajpert-De Meyts E. Pathogenesis of germ cell neoplasia in testicular dysgenesis and disorders of sex development. Semin Cell Dev Biol. 2015;45:124-137.

52. Petersen PM, et al. Impaired testicular function in patients with carcinoma-in-situ of the testis. J Clin Oncol. 1999;17(1):173-179.

53. Mitchell RT, et al. Anogenital distance plasticity in adulthood: implications for its use as a biomarker of fetal androgen action. Endocrinology. 2015;156(1):24-31.

54. Fowler PA, Bhattacharya S, Flannigan S, Drake AJ, O'Shaughnessy PJ. Maternal cigarette smoking and effects on androgen action in male offspring: unexpected effects on second-trimester anogenital distance. J Clin Endocrinol Metab. 2011;96(9):E1502-E1506.

55. van den Driesche S, et al. Prolonged exposure to acetaminophen reduces testosterone production by the human fetal testis in a xenograft model. Sci Transl Med. 2015;7(288):288ra80.

56. Fisher BG, Thankamony A, Hughes IA, Ong KK, Dunger DB, Acerini CL. Prenatal paracetamol exposure is associated with shorter anogenital distance in male infants. Hum Reprod. 2016;31(11):2642-2650.

57. Lind DV, et al. Maternal use of mild analgesics during pregnancy associated with reduced anogenital distance in sons: a cohort study of 1027 mother-child pairs. Hum Reprod. 2017;32(1):223-231.

58. van den Driesche $\mathrm{S}$, et al. Comparative effects of di(n-butyl) phthalate exposure on fetal germ cell development in the rat and in human fetal testis xenografts. Environ Health Perspect. 2015;123(3):223-230.

59. Vassilakopoulou M, Boostandoost E, Papaxoinis G, de La Motte Rouge T, Khayat D, Psyrri A. Anticancer treatment and fertility: Effect of therapeutic modalities on reproductive system and functions. Crit Rev Oncol Hematol. 2016;97:328-334.

60. Gupta G, Maikhuri JP, Dwivedi AK, Dhar JD, Setty BS. Changes in daily sperm production rate in rats under the influence of a potent antispermatogenic agent, CDRI 84/35. Contraception. 1999;59(6):401-404.

61. Kim IS. Effects of exposure of lactating female rats to polychlorinated biphenyls (Pcbs) on testis weight, sperm production and sertoli cell numbers in the adult male offspring. J Vet Med Sci. 2001;63(1):5-9.

62. Swan SH, et al. Decrease in anogenital distance among male infants with prenatal phthalate exposure. Environ Health Perspect. 2005;113(8):1056-1061.

63. Bornehag CG, et al. Prenatal phthalate exposures and anogenital distance in Swedish boys. Environ Health Perspect. 2015;123(1):101-107. 
64. Lambrot R, et al. Phthalates impair germ cell development in the human fetal testis in vitro without change in testosterone production. Environ Health Perspect. 2009;117(1):32-37.

65. Mitchell RT, et al. Do phthalates affect steroidogenesis by the human fetal testis? Exposure of human fetal testis xenografts to di-n-butyl phthalate. J Clin Endocrinol Metab. 2012;97(3):E341-E348.

66. Heger NE, et al. Human fetal testis xenografts are resistant to phthalate-induced endocrine disruption. Environ Health Perspect. 2012;120(8):1137-1143.

67. Spencer JR, Torrado T, Sanchez RS, Vaughan ED, Imperato-McGinley J. Effects of flutamide and finasteride on rat testicular descent. Endocrinology. 1991;129(2):741-748.

68. Clark RL, et al. Critical developmental periods for effects on male rat genitalia induced by finasteride, a 5 alpha-reductase inhibitor. Toxicol Appl Pharmacol. 1993;119(1):34-40.

69. Foster PM, Harris MW. Changes in androgen-mediated reproductive development in male rat offspring following exposure to a single oral dose of flutamide at different gestational ages. Toxicol Sci. 2005;85(2):1024-1032.

70. Scott HM, Mason JI, Sharpe RM. Steroidogenesis in the fetal testis and its susceptibility to disruption by exogenous compounds. Endocr Rev. 2009;30(7):883-925.

71. Rud CN, Daugaard G, Rajpert-De Meyts E, Skakkebæk NE, Petersen JH, Jørgensen N. Sperm concentration, testicular volume and age predict risk of carcinoma in situ in contralateral testis of men with testicular germ cell cancer. J Urol. 2013;190(6):2074-2080.

72. Hutchison GR, et al. The origins and time of appearance of focal testicular dysgenesis in an animal model of testicular dysgenesis syndrome: evidence for delayed testis development? Int J Androl. 2008;31(2):103-111.

73. Hutchison GR, et al. Sertoli cell development and function in an animal model of testicular dysgenesis syndrome. Biol Reprod. 2008;78(2):352-360

74. Mitchell RT, et al. Germ cell differentiation in the marmoset (Callithrix jacchus) during fetal and neonatal life closely parallels that in the human. Hum Reprod. 2008;23(12):2755-2765.

75. Atanassova N, et al. Permanent effects of neonatal estrogen exposure in rats on reproductive hormone levels, Sertoli cell number, and the efficiency of spermatogenesis in adulthood. Endocrinology. 1999;140(11):5364-5373.

76. Sharpe RM, et al. Infant feeding with soy formula milk: effects on the testis and on blood testosterone levels in marmoset monkeys during the period of neonatal testicular activity. Hum Reprod. 2002;17(7):1692-1703.

77. Welsh M, Saunders PT, Atanassova N, Sharpe RM, Smith LB. Androgen action via testicular peritubular myoid cells is essential for male fertility. FASEB J. 2009;23(12):4218-4230.

78. Paul C, Rhind SM, Kyle CE, Scott H, McKinnell C, Sharpe RM. Cellular and hormonal disruption of fetal testis development in sheep reared on pasture treated with sewage sludge. Environ Health Perspect. 2005;113(11):1580-1587.

79. Tyndall V, Broyde M, Sharpe R, Welsh M, Drake AJ, McNeilly AS. Effect of androgen treatment during foetal and/or neonatal life on ovarian function in prepubertal and adult rats. Reproduction. 2012;143(1):21-33.

80. Parra MD, Mendiola J, Jørgensen N, Swan SH, Torres-Cantero AM. Anogenital distance and reproductive parameters in young men. Andrologia. 2016;48(1):3-10.

81. Cox K, et al. Shorter anogenital distance and anoscrotal distance correlate with severity of hypospadias: a prospective study. $J$ Pediatr Urol. 2016;13(1): 57.e1-57.e5. 